Institute for Research on Poverty

Discussion Paper no. 1214-00

\title{
Interpreting Minimum Wage Effects on Wage Distributions: A Cautionary Tale
}

\author{
Christopher J. Flinn \\ Department of Economics \\ New York University \\ E-mail: christopher.flinn@ @yu.edu
}

October 2000

This research has been partially supported by the W.E. Upjohn Institute for Employment Research, ICER (Torino), and the C.V. Starr Center for Applied Economics at NYU. I am grateful to these organizations and to the Dipartimento di Economia of the Universitá di Torino for its hospitality. I have received helpful comments from Gerard van den Berg, Mario Catalani, Robert Moffitt, Geert Ridder, Coen Teulings, and seminar participants in a number of venues. I am especially grateful for the detailed comments and helpful advice received from Rolf Aaberge and Bernard Selanié. John Wolf of the Institute for Research on Poverty provided helpful editorial advice. I remain solely responsible for all errors, omissions, and interpretations.

IRP publications (discussion papers, special reports, and the newsletter Focus) are available on the Internet. The IRP Web site can be accessed at the following address: http://www.ssc.wisc.edu/irp/ 


\begin{abstract}
It is tempting to try to infer the welfare effects of minimum wage changes from empirical observations on pre- and post change employment and unemployment levels and wage or earnings distributions. Using a simple model of search, matching, and bargaining, I characterize the relationship between minimum wage levels, labor market outcomes, and the welfare of labor market participants. Using observations on wage distributions before and after changes in the nominal minimum wage, I determine what can and cannot be learned about welfare impacts from changes in various features of these distributions. Results are illustrated using simulation exercises and a small empirical example. Using U.S. data for young labor market participants in March 1997 and March 1998, this study concludes that the increase in the minimum wage which occurred in September 1997 may have been welfareenhancing, though various implications of the model are not consistent with the data. This analysis illustrates the fact that well-specified behavioral models are required to evaluate the impact of changes in institutional constraints on the welfare of labor market participants.
\end{abstract}




\section{Interpreting Minimum Wage Effects on Wage Distributions: A Cautionary Tale}

\section{INTRODUCTION}

It is tempting to try to infer the welfare effects of actual minimum wage changes from empirical observations on pre- and post-change employment and unemployment levels and wage or earnings distributions. For example, minimum wage increases are often explicitly or implicitly taken to be beneficial for the impacted population if changes in group employment rates are found to be positive or only slightly negative. As another example, although a very small percentage of U.S. workers are paid the minimum wage, larger impacts on welfare within the general population are often taken to result from a sort of "ripple" effect from the bottom up, which in terms of the wage distribution itself is often referred to as spillover. Empirical evidence that demonstrates a change in the shape of the wage distribution above the minimum wage is often interpreted as resulting from these spillover effects, and by their very nature these are assumed to be beneficial for individuals on the supply side of the market.

In this paper I shall rigorously attempt to rigorously define, characterize, and explain the phenomenon of spillover. To accomplish this task, I will use a simple model of search and bargaining in a stationary environment. While the model is admittedly highly stylized, in a companion paper (Flinn 1999) I show that it can be estimated using Current Population Survey (CPS) data and that it fits observed wage and unemployment duration distributions quite well. Thus the model at a minimum provides a parsimonious and readily interpretable view of the labor market as it is reflected in CPS data, and for this reason can be given some credibility. The model is readily adapted to allow for the existence of binding minimum wages rates. The equilibrium which results from the imposition of a minimum wage [or an increase in value of an 
already binding minimum wage] is roughly in accordance with empirical work on this subject based on disaggregated data. In particular, a few of the implications of the model are: (1) the existence of a probability mass at the minimum wage $m$ with an absolutely continuous distribution to the right of $m$; (2) decreases in employment rates with increases in the minimum wage; and (3) the possible existence of spillover effects in response to a change in the minimum wage rate. Using the model, I will rigorously define a particular welfare measure as well as "spillovers." ${ }^{1}$ I show that welfare in the population can increase even though employment rates decrease, and with or without "spillovers" in the wage distribution. Conversely, spillover effects of minimum wage changes do not indicate that the change was necessarily welfare-enhancing. The main point to which I want to draw attention is that the welfare effects of minimum wage changes can only be inferred by using empirical evidence on employment rates, wage distributions, and a formal model within which welfare can be rigorously defined and evaluated.

I will not be directly concerned with the impacts of minimum wage levels on unemployment or employment levels in this paper. Instead, I will use the model to attempt to understand the impact of minimum wage levels on accepted wage offer distributions, both in terms of truncation and shape-changing. Several authors have attempted to adapt standard econometric models for truncated and limited dependent variables to incorporate minimum wages into standard wage function estimation schemes. Some of the more important research efforts in this area include Meyer and Wise (1983a,1983b), Dinardo et al. (1996), and Dickens et al. (1997). Meyer and Wise estimated a model of minimum wage effects using individual-level data which allowed them to infer what the wage distribution and employment level would have been in the

\footnotetext{
${ }^{1}$ The definition of spillover we will use turns out to be identical to how the notion is defined in Assumption 1 of Dinardo et al. (1996). While they utilize an assumption regarding the extent of spillover in the wage distribution to perform a statistical decomposition of probability density functions, we will be interested in using the definition to formulate a nonparametric test for the existence of spillovers.
} 
absence of a minimum wage. The basic idea behind the econometric specification is to assume the form of the wage distribution in the absence of a minimum wage, and then to allow the minimum wage to alter this distribution by essentially aggregating probability mass around the minimum wage to that exact value. This results in a wage distribution which has a continuous and discrete component to it. Although their model specification has been criticized by a number of researchers [e.g., Card and Krueger (1995, pp. 232-236) and Dickens et al. (1997)], primarily for relying on functional form assumptions for identification and for choosing a parameterization which rules out the possibility of employment increases in response to a minimum wage increase, it remains one of the better econometric attempts to identify minimum wage effects using individual-level data in the literature. ${ }^{2}$ From my perspective, the main weakness of their model is the arbitrary specification of the manner in which a minimum wage "distorts" the preexisting distribution wage distribution. In the model developed here and in the companion paper (Flinn 1999), optimizing behavior by searchers and firms determines the nature of this "distortion," and it is roughly consistent both with the Meyer and Wise econometric specification and with the empirical evidence cited in Card and Krueger.

The Dickens et al. paper attempts to compare wage distributions before and after changes in the minimum wage in order to infer employment effects. To estimate employment impacts, they replace the Meyer and Wise identification condition that the minimum wage has no impact on the distribution of wages immediately above it with the condition that it has no impact on the wage distribution above some value $x \gg m$. While this assumption seems reasonable on the face of it, it will not in general be valid within the simple equilibrium framework developed here. In addition, as I have argued above, the ultimate goal of empirical wage research should probably be

\footnotetext{
${ }^{2}$ For another good example, see Heckman and Sedlacek (1981).
} 
directed to determining welfare rather than employment impacts.

The focus of the Dinardo et al paper is on assessing the impacts of minimum wages and other institutional features of the labor market on wage distributions. To perform their semiparametric statistical analysis, they are forced to make a number of rather controversial assumptions regarding the manner in which minimum wage changes impact both the wage distribution and employment rates. The wage distributions they fit also have the unfortunate characteristic of being everywhere continuous, which rules out the spike at the minimum which is clearly observable in U.S. data, particularly for young and female dependent workers. While the goal of the analysis is to determine the impact of various institutional features of the labor market [one of which is the minimum wage] on the increasing levels of wage inequality observed over the past two decades in the United.States, the paper does not take a clear position on whether such increasing inequality is good or bad. The model in this paper and some of the examples presented make it clear that "cross-sectional' inequality may indeed be a good thing.

There are a number of ways to include minimum wages in equilibrium models of the labor market. In terms of my work, some of the more relevant theoretical, econometric, and empirical contributions to this literature include Eckstein and Wolpin (1990), Mortensen (1990), Burdett and Mortensen (1998), van den Berg and Ridder (1998), and Bontemps, Robin, and van den Berg (1999). In these models, which are not based on matching and bargaining but instead utilize assumptions of wage-posting by homogeneous or heterogeneous firms, minimum wage restrictions do not typically result in mass points in the wage distribution at the minimum, and in a number of cases the wage distributions implied by the theory are grossly at odds with empirical observation. ${ }^{3}$ However, this class of models contains examples of situations in which the

\footnotetext{
${ }^{3}$ A notable exception to this statement can be found in Bontemps, Robin, and van den Berg (2000), which provides
} 
imposition of minimum wages can be Pareto welfare-improving and allow for a number of labor market phenomena that cannot be captured within our framework. All of the various equilibrium labor market models based on search-theoretic foundations have their advantages and disadvantages, but my feeling was that a model based explicitly on bilaterial bargaining between a given worker and firm may provide a slightly preferable framework in which to analyze disaggregated labor market data.

The plan of the paper is as follows. In Section 2 I develop a bargaining model in a continuous-time search environment both in the absence and in the presence of a binding minimum wage. Section 3 contains a discussion of one measure of population welfare and its relation to the minimum wage level. I also provide results and examples illustrating the impact of minimum wages on the wage distribution and the relationship between changes in welfare levels and wage distributions. In Section 4 I simulate the behavioral model under alternative specifications of the labor market environment to demonstrate some of the theoretical results obtained in Section 3. Section 5 contains a small empirical exercise in which I look at changes in the wage distribution of 16- to 24-year-old workers between March 1997 and March 1998; between these two dates the minimum wage changed from $\$ 4.75$ to $\$ 5.15$ an hour [in September 1997]. A brief conclusion is offered in Section 6 .

\section{Labor Market Search with Bargaining}

In this section I describe the behavioral model of labor market search with matching and bargaining. The model is formulated in continuous time and assumes stationarity of the labor market environment. In the first subsection I derive the decision rules for terminating search and for dividing the match value between worker and firm in the absence of minimum wages. These

a perfect fit to the data at the expense of uniqueness of equilibrium and analytical complexity. 
results are relatively well-known, and are mainly presented to set ideas and for purposes of comparison with the case in which a binding minimum wage is present, which is analyzed in the following subsection.

Throughout I assume that there exists an invariant, technologically determined distribution of worker-firm productivity levels which is given by $G(\theta)$. When a potential employee and a firm meet, which happens at rate $\lambda$, the productive value of the match $(\theta)$ is immediately observed by both the applicant and the firm. At this point a division of the match value is proposed using a Nash bargaining framework. The searcher's instantaneous discount rate is given by $\rho>0$. The rate of (exogenous) termination of employment contracts is $\eta \geq 0$. While unemployed individuals search, their instantaneous utility is given by $b$, which can assume positive or negative values. For simplicity, I assume that employed individuals do not receive alternative offers of employment, i.e., there is no on-the-job search. It is straightforward to adapt the current framework to that case, however.

\subsection{Labor Market Decisions without Minimum Wages}

I assume that the only factor of production is labor, and that total output of the firm is simply the sum of the productivity levels of all of its employees. Then if the firm "passes" on the applicant - that is, does not make an employment offer - its "disagreement" outcome is 0 [it

earns no revenue but makes no wage payment]. The applicant's disagreement value is the value of continued search, which we denote $V_{n}$. For any given value of $V_{n}$ there exists a corresponding critical "match" value $\theta^{*}=\rho V_{n}$ ( $\rho$ is the instantaneous discount rate), which has the property that all matches with values at least as great as $\theta^{*}$ will result in employment while all those 
matches of lower value will not. For any $\theta \geq \theta^{*}$, the wage offer is given by

$$
w\left(\theta, V_{n}\right)=\arg \max _{w}\left[V_{e}(w)-V_{n}\right]^{\alpha}\left[\frac{\theta-w}{\rho+\eta}\right]^{1-\alpha}
$$

where without loss of generality it has been assumed that the firm shares the employee's effective rate of discount, $\rho+\eta$.

The value of employment at a wage of $w$ is easily determined. Consider an infinitesimally small period of time $\Delta t$. Over this "period," either the individual will continue to be employed at wage $w$ or will lose her job, which occurs at rate $\eta$. Then

$$
V_{e}(w)=\frac{w \Delta t}{1+\rho \Delta t}+\frac{1}{1+\rho \Delta t}\left[\eta \Delta t V_{n}+(1-\eta \Delta t) V_{e}(w)\right]+\frac{o(\Delta t)}{1+\rho \Delta t}
$$

where the term $(1+\rho \Delta t)^{-1}$ is an "infinitesimal" discount factor associated with the small interval $\Delta t, \eta \Delta t$ is the approximate probability of being terminated from one's current employment by the end of $\Delta t$, and $o(\Delta t)$ is a term which has the property that $\lim _{\Delta t \rightarrow 0}(o(\Delta t) / \Delta t)=0$. The first term on the right-hand side of [2] is the value of the wage payment over the interval, which is the total payment $w \Delta t$ multiplied by the "instantaneous" discount factor [think of the payment as being received at the end of the interval $\Delta t]$. After collecting terms and taking the limit of [2] as $\Delta t \rightarrow 0$, we have

$$
V_{e}(w)=\frac{w+\eta V_{n}}{\rho+\eta}
$$


I now substitute [3] into [1] so as to simplify the problem as follows:

$$
\begin{aligned}
V_{e}(w)-V_{n} & =\frac{w+\eta V_{n}}{\rho+\eta}-V_{n} \\
& =\frac{w-\rho V_{n}}{\rho+\eta},
\end{aligned}
$$

which results in the well-known expression

$$
\begin{aligned}
w\left(\theta, V_{n}\right) & =\arg \max _{w}\left[w-\rho V_{n}\right]^{\alpha}[\theta-w]^{1-\alpha} \\
& =\alpha \theta+(1-\alpha) \rho V_{n} .
\end{aligned}
$$

I now move on to compute the value of nonemployment. Using the same setup as above for defining the value of employment, we begin with the $\Delta t$-period formulation, which is

$$
\begin{aligned}
& V_{n}=\frac{b \Delta t}{1+\rho \Delta t}+\frac{1}{1+\rho \Delta t}\left\{\lambda \Delta t \int \max \left[V_{n}, V_{e}\left(w\left(\theta, V_{n}\right)\right)\right] d G(\theta)\right. \\
& \left.+(1-\lambda \Delta t) V_{n}\right\}+\frac{o(\Delta t)}{1+\rho \Delta t},
\end{aligned}
$$

where $\lambda \Delta t$ is the approximate probability of encountering one potential employer over the interval. Rearranging and taking limits, we have

$$
\rho V_{n}=b+\lambda \int_{\rho V_{n}}\left[V_{e}\left(w\left(\theta, V_{n}\right)\right)-V_{n}\right] d G(\theta) .
$$


Since

$$
\begin{aligned}
V_{e}\left(w\left(\theta, V_{n}\right)\right) & =\frac{\alpha \theta+(1-\alpha) \rho V_{n}+\eta V_{n}}{\rho+\eta} \\
& =\frac{\alpha \theta-\alpha \rho V_{n}}{\rho+\eta}+V_{n},
\end{aligned}
$$

we have

$$
V_{e}\left(w\left(\theta, V_{n}\right)\right)-V_{n}=\frac{\alpha \theta-\alpha \rho V_{n}}{\rho+\eta}
$$

Then the final (implicit) expression for the value of search is

$$
\rho V_{n}=b+\frac{\alpha \lambda}{\rho+\eta} \int_{\rho V_{n}}\left[\theta-\rho V_{n}\right] d G(\theta) .
$$

Note that this expression is identical to the expression for the reservation value in a model with no bargaining when $\theta$ is the payment to the individual except for the presence of the factor $\alpha$ [see Flinn and Heckman (1982)]. This is not unexpected since when $\alpha=1$, the entire match value is transferred to the worker, and thus search over $\theta$ is the same as search over $w$.

I can now summarize the important properties of the model. The critical "match" value $\theta^{*}$ is equal to $\rho V_{n}$, which is defined by [4]. Since at this match value the wage payment is equal to $w^{*} \equiv w\left(\theta^{*}, V_{n}\right)=\alpha \theta^{*}+(1-\alpha) \theta^{*}=\theta^{*}$, the reservation wage is identical to the reservation match value. The probability that a random encounter generates an acceptable match is given by $\tilde{G}\left(\theta^{*}\right)$, where $\tilde{G}$ denotes the survivor function, $1-G$. The rate of leaving unemployment is $\lambda \tilde{G}\left(\theta^{*}\right)$. As we can see from [4], since $\theta^{*}$ is an increasing function of $\alpha$, rates of unemployment are higher when searchers have more bargaining power. 
The observed wage density is a simple mapping from the matching density. Since

$$
\begin{aligned}
w\left(\theta, V_{n}\right) & =\alpha \theta+(1-\alpha) \theta^{*} \\
\Rightarrow \tilde{\theta}\left(w, V_{n}\right) & =\frac{w-(1-\alpha) \theta^{*}}{\alpha},
\end{aligned}
$$

then the density function of observed wages is given by

$$
h(w)=\left\{\begin{array}{ll}
\frac{\alpha^{-1} g\left(\tilde{\theta}\left(w, V_{n}\right)\right)}{\tilde{G}\left(\theta^{*}\right)} & w \geq \theta^{*} \\
0 & w<\theta^{*}
\end{array} .\right.
$$

An example helps to illustrate the structure of the model both with and without binding minimum wages. The rate of arrival of offers $(\lambda)$ is set to the value .5 (so that job contacts occur every 2 "periods" on average), the rate of job dissolutions $(\eta)$ is set to .02 (so that the average length of a job is 50 periods), $\rho$ is set to .01 , and the instantaneous return from search $(b)$ is set to -1. The firm-searcher matching distribution is assumed to be uniform with support $[0,10]$. I compute the equilibrium wage distribution for values of $\alpha$ in the set $\{.25, .50, .75,1.00\}$.

Figure 1.a plots the uniform p.d.f. that represents $g(\theta)$ in this case. Figure 1.b plots the mapping from draws of $\theta$ into wage offers under the four alternative values of $\alpha$, that is $w_{\alpha}\left(\theta, V_{n}(\alpha)\right)=\alpha \theta+(1-\alpha) \rho V_{n}(\alpha)$. Note that $\alpha$ affects the equilibrium mapping both directly through the slope and indirectly through the disagreement point $\rho V_{n}(\alpha)$. Figures 1.c-f plot the equilibrium wage p.d.f.s for the four $\alpha$ values. Increasing $\alpha$ in the uniform case simply results in increases in the lower and upper bound of the support of the equilibrium wage distribution, which is itself uniform. Since increases in $\alpha$ result in increases in the value of search, it is interesting to note that in this case an increasing mean wage and an increasing dispersion in the wage 
distribution are associated with higher values of search.

2.2. Labor Market Decisions in the Presence of Minimum Wages

Now consider the case in which the interactions between applicants and firms are constrained by the presence of a minimum wage. The minimum wage, $m$, is set by the government and is assumed to apply to all potential matches. I assume that the only compensation provided by the firm is the wage. Thus there are no other forms of compensation the firm can adjust so as to "undo" the minimum wage payment requirement.

I impose the minimum wage in the framework established in the previous section. As should be clear, any $m \leq \theta^{*}$ has no effect on the behavior of applicants or firms and thus would be a meaningless constraint. Thus I consider only the effects of an imposition of $m>\theta^{*}$.

Recall that the expected value of the match from the point of view of the firm is proportional to $(\theta-w)$. Firms cannot earn positive profits on matches which have a value less than $m$. Since $m>\theta^{*}$, an immediate implication of the imposition of the minimum wage is that fewer contacts will result in jobs - the standard employment effect.

In terms of wage payments, the minimum wage acts solely as a side constraint on the Nash bargaining problem. Formally, the revised problem is given by

$$
w\left(\theta, V_{n}\right)=\arg \max _{w \geq m}\left[V_{e}(w)-V_{n}\right]^{\alpha}\left[\frac{\theta-w}{\rho+\eta}\right]^{1-\alpha}
$$

where the only difference from [1] is the restriction $w \geq m$. The effect on the solution is relatively intuitive. Under the "constrained" Nash bargaining problem, there will exist a value of search which we denote $\tilde{V}_{n}(m)$ [note that this value is not equal to the $V_{n}$ which we defined in the unconstrained problem - it will be defined below]. If we ignore the minimum wage constraint in 
determining the wage payment given a match value of $\theta$ and the search value $\tilde{V}_{n}(m)$, we get

$$
\tilde{w}\left(\theta, \tilde{V}_{n}(m)\right)=\alpha \theta+(1-\alpha) \rho \tilde{V}_{n}(m)
$$

Under this division of the match value, the worker would receive a wage of $m$ when $\theta=\hat{\theta}$, where

$$
\hat{\theta}\left(m, \tilde{V}_{n}(m)\right)=\frac{m-(1-\alpha) \rho \tilde{V}_{n}(m)}{\alpha} .
$$

Then if $\hat{\theta} \leq m$, all "feasible" matches would generate wage offers at least as large as $m$. When $\hat{\theta}>m$, this is not the case. When $\theta$ belongs to the set $[m, \hat{\theta})$, the offer according to [5] is less than $m$. However, when confronted with the choice of giving some of its surplus to the worker versus a return of 0 , the firm pays the wage of $m$ for all $\theta \in[m, \hat{\theta})$. Wages for acceptable $\theta$ outside of this set are determined according to [5].

I can now consider the individual's search problem given this wage offer function. Using the $\Delta t$ interval formulation,

$$
\begin{aligned}
\tilde{V}_{n}(m)= & \frac{b \Delta t}{1+\rho \Delta t}+\frac{\lambda \Delta t}{1+\rho \Delta t}\left\{\int_{m}^{\hat{\theta}\left(m, \tilde{V}_{n}(m)\right)}\left[\frac{m+\eta \tilde{V}_{n}(m)}{\rho+\eta}\right] d G(\theta)\right. \\
& \left.+\int_{\hat{\theta}\left(m, \tilde{V}_{n}(m)\right)}\left[\frac{\alpha \theta+(1-\alpha) \rho \tilde{V}_{n}(m)+\eta \tilde{V}_{n}(m)}{\rho+\eta}\right] d G(\theta)+\tilde{V}_{n}(m) G(m)\right\} \\
& +\frac{(1-\lambda \Delta t)}{1+\rho \Delta t} \tilde{V}_{n}(m)+\frac{o(\Delta t)}{1+\rho \Delta t} .
\end{aligned}
$$


Taking limits after collecting terms, we have

$$
\begin{aligned}
\rho \tilde{V}_{n}(m)= & b+\frac{\lambda}{\rho+\eta}\left\{\int_{m}^{\hat{\theta}\left(m, \tilde{V}_{n}(m)\right)}\left[m-\rho \tilde{V}_{n}(m)\right] d G(\theta)\right. \\
& \left.+\alpha \int_{\hat{\theta}\left(m, \tilde{V}_{n}(m)\right)}\left[\theta-\rho \tilde{V}_{n}(m)\right] d G(\theta)\right\} \\
= & b+\frac{\lambda}{\rho+\eta}\left\{\left[\tilde{G}(m)-\tilde{G}\left(\frac{m-(1-\alpha) \rho V_{n}(m)}{\alpha}\right)\right]\left[m-\rho \tilde{V}_{n}(m)\right]\right. \\
& \left.+\alpha \int_{\hat{\theta}\left(m, \tilde{V}_{n}(m)\right)}\left[\theta-\rho \tilde{V}_{n}(m)\right] d G(\theta)\right\} .
\end{aligned}
$$

It makes some sense to refer to the vale $\rho \tilde{V}_{n}(m)$ as the "implicit" reservation wage. Unlike the situation in which a binding minimum wage does not exist, this value is not the minimal acceptable wage and match value. The acceptable wage/match value is rather the imposed minimum value $m$. Nonetheless, the value $\rho \tilde{V}_{n}$ is of critical importance in determining equilibrium wages and the welfare effects of minimum wage changes.

Conditional on the value of a binding minimum wage $m$, the equilibrium wage distribution is described by

$$
p(w \mid m)=\left\{\begin{array}{cc}
\frac{\alpha^{-1} g\left(\tilde{\theta}\left(w, \tilde{V}_{n}\right)\right)}{\tilde{G}(m)} & w>m \\
\frac{G\left(\hat{\theta}\left(m, \tilde{V}_{n}\right)-G(m)\right.}{\tilde{G}(m)} & w=m \\
0 & w<m .
\end{array}\right.
$$

The minimum wage side constraint produces an equilibrium wage distribution which has a mass point at $m$ and has wages being continuously distributed on the interval $(m, \infty){ }^{4}$

Let us reconsider the uniform example after a minimum wage of 7.5 has been imposed; since the distribution now has a mass point, it is more convenient to plot the c.d.f. than the p.d.f.

\footnotetext{
${ }^{4}$ This statement is predicated on $\theta$ being a continuously distributed random variable with unbounded support.
} 
Figure 2.a plots the c.d.f. of the matching distribution. Figure 2.b contains the equilibrium wage offer mapping from $\theta$ to $w$ when $m=7.5$. For the case of $\alpha=.25$, the equilibrium wage function maps all values of $\theta \geq 7.5$ into a wage offer of $w=7.5$. At least when the distribution $G$ has bounded support, this demonstrates that the imposition of a minimum wage can result in a degenerate wage offer distribution at the minimum, as we see in Figure 2.c. In the case of $\alpha=.5$ (Figure 2.d), the equilibrium wage distribution has a substantial mass point at 7.5 , with a relatively "narrow" range of wages above it. When $\alpha=.75$ or 1 (Figures 2.e and 2.f), the minimum wage does not substantially affect the equilibrium wage distribution, which is not to say that the welfare effects of the imposition of such a minimum wage in these cases are inconsequential.

\section{Minimum Wage Effects on Welfare and Wage Distributions}

In Flinn (1999) I provide an extensive discussion of some possible measures of welfare that can be developed using this labor market model. I focus on one simple measure here, which is the value of unemployed search given the minimum wage $m$, or $\tilde{V}_{n}(m)$. It is convenient to work with this measure because it is both a scalar and readily interpretable. Since all individuals begin their labor market careers in the unemployment state, $\tilde{V}_{n}(m)$ represents the ex ante value of the labor market career for individuals inhabiting a labor market characterized by $\Psi \equiv(\rho \lambda \mu \alpha \eta)^{\prime}$ when the minimum wage is set at the level $m$ forever. While it is clear that minimum wages do change over time, as do other labor market parameters, such a measure is consistent with my modeling assumption of stationarity. Readers interested in the development of other welfare measures can consult Flinn (1999).

Note that I do not consider the welfare of firms either explicitly or implicitly. Clearly, when a minimum wage results in an increase in the value of search for individuals on the supply 
side of the market, the proportion of the match-specific surplus available to firms is diminished. Thus, there are no Pareto-maximizing minimum wages for the economy as a whole in this framework. Nonetheless, under any minimum wage firms continue to earn nonnegative profits on all employment contracts. Since the empirical component of my research uses data exclusively from the supply side of the market, for pragmatic reasons I can only attempt to characterize and compare labor market and welfare outcomes for individuals in any event.

\subsection{Results Using Unconditional Wage Distributions}

Within this model the effects of imposing a minimum wage on the accepted wage distribution are complex. The minimum observed wage will always increase in response to the imposition of a binding minimum wage or when a binding minimum wage is increased. While intuition might lead one to expect that comparing wage distributions associated with the same labor market environment $\Psi$ and different minimum wage levels in terms of first order stochastic dominance criteria might be a reliable guide to underlying welfare levels, this is not typically the case. Using the welfare criterion I have defined above, the fact that the wage distribution under the new [higher] minimum wage does not first order stochastically dominate the old one is informative about welfare, but the converse is not the case. I now provide the demonstration of this claim.

Definition 1 Distribution $F_{2}$ first order stochastically dominates distribution $F_{1}$ if $F_{1}(x) \geq F_{2}(x)$ for all $x$ and $F_{1}(x)>F_{2}(x)$ for some $x$.

In terms of the model, we have the following result.

Proposition 2 Let the wage distribution under the minimum wage $m^{\prime}$ be given by $F_{2}(w)$ and 
that under $m$ be given by $F_{1}(w)$, for $m<m^{\prime}$. Then $F_{2}$ first order stochastically dominates $F_{1}$ iff

$$
\frac{\tilde{G}(m)}{\tilde{G}\left(m^{\prime}\right)} \geq \frac{\tilde{G}\left(\frac{z-(1-\alpha) \rho \tilde{V}_{n}(m)}{\alpha}\right)}{\tilde{G}\left(\frac{z-(1-\alpha) \rho \tilde{V}_{n}\left(m^{\prime}\right)}{\alpha}\right)} \text { for all } z \geq m^{\prime}
$$

Proof. Clearly $F_{1}(w)>F_{2}(w)$ for all $w<m^{\prime}$, since $F_{2}(w)=0$ for all $w<m^{\prime}$. For any $z \geq m^{\prime}$,

$$
F_{2}(z)=1-\frac{\tilde{G}\left(\frac{z-(1-\alpha) \rho \tilde{V}_{n}\left(m^{\prime}\right)}{\alpha}\right)}{\tilde{G}\left(m^{\prime}\right)}
$$

and

$$
F_{1}(z)=1-\frac{\tilde{G}\left(\frac{z-(1-\alpha) \rho \tilde{V}_{n}(m)}{\alpha}\right)}{\tilde{G}(m)}
$$

so that

$$
\begin{aligned}
F_{1}(z) & \geq F_{2}(z) \\
\Leftrightarrow 1-\frac{\tilde{G}\left(\frac{z-(1-\alpha) \rho \tilde{V}_{n}(m)}{\alpha}\right)}{\tilde{G}(m)} & \geq 1-\frac{\tilde{G}\left(\frac{z-(1-\alpha) \rho \tilde{V}_{n}\left(m^{\prime}\right)}{\alpha}\right)}{\tilde{G}\left(m^{\prime}\right)} \\
\Leftrightarrow \frac{\tilde{G}\left(\frac{z-(1-\alpha) \rho \tilde{V}_{n}\left(m^{\prime}\right)}{\alpha}\right)}{\tilde{G}\left(m^{\prime}\right)} & \geq \frac{\tilde{G}\left(\frac{z-(1-\alpha) \rho \tilde{V}_{n}(m)}{\alpha}\right)}{\tilde{G}(m)} \\
\Leftrightarrow \frac{\tilde{G}(m)}{\tilde{G}\left(m^{\prime}\right)} & \geq \frac{\tilde{G}\left(\frac{z-(1-\alpha) \rho \tilde{V}_{n}(m)}{\alpha}\right)}{\tilde{G}\left(\frac{z-(1-\alpha) \rho \tilde{V}_{n}\left(m^{\prime}\right)}{\alpha}\right)} .
\end{aligned}
$$

Corollary 3 F $F_{2}$ first order stochastically dominates $F_{1}$ if $\tilde{V}_{n}\left(m^{\prime}\right) \geq \tilde{V}_{n}(m)$.

Proof. The left-hand side of [10] is by construction greater than or equal to 1 . Then the 
inequality is satisfied since

$$
\begin{aligned}
\tilde{V}_{n}\left(m^{\prime}\right) & \geq \tilde{V}_{n}(m) \\
\Rightarrow \frac{z-(1-\alpha) \rho \tilde{V}_{n}\left(m^{\prime}\right)}{\alpha} & \leq \frac{z-(1-\alpha) \rho \tilde{V}_{n}(m)}{\alpha} \\
\Rightarrow \frac{\tilde{G}\left(\frac{z-(1-\alpha) \rho \tilde{V}_{n}(m)}{\alpha}\right)}{\tilde{G}\left(\frac{z-(1-\alpha) \rho \tilde{V}_{n}\left(m^{\prime}\right)}{\alpha}\right)} & \leq 1 .
\end{aligned}
$$

Unfortunately, this result is not of much practical significance since $\tilde{V}_{n}\left(m^{\prime}\right) \geq \tilde{V}_{n}(m)$ is only a sufficient condition for stochastic dominance of $F_{2}$ with respect to $F_{1}$, not a necessary condition. A more practically useful result is the following.

Corollary $4 \quad F_{2}$ does not first order stochastically dominate $F_{1}$ if $\tilde{V}_{n}\left(m^{\prime}\right)<\tilde{V}_{n}(m)$.

Proof. For $F_{2}$ not to first order stochastically dominate $F_{1}$ implies the existence of at least one $x$ such that

$$
\begin{aligned}
\frac{\tilde{G}\left(\frac{x-(1-\alpha) \rho \tilde{V}_{n}(m)}{\alpha}\right)}{\tilde{G}\left(\frac{x-(1-\alpha) \rho \tilde{V}_{n}\left(m^{\prime}\right)}{\alpha}\right)} & >\frac{\tilde{G}(m)}{\tilde{G}\left(m^{\prime}\right)}>1 \\
\Rightarrow \frac{x-(1-\alpha) \rho \tilde{V}_{n}(m)}{\alpha} & <\frac{x-(1-\alpha) \rho \tilde{V}_{n}\left(m^{\prime}\right)}{\alpha} \\
\Rightarrow \tilde{V}_{n}(m) & >\tilde{V}_{n}\left(m^{\prime}\right) .
\end{aligned}
$$

These results suggest that observed wage distributions before and after minimum wage changes can reveal whether the minimum wage increase worsened welfare, but cannot be used to infer whether welfare increased. In particular, the finding that the new wage distribution, $F_{2}$, first 
order stochastically dominates the old one is consistent with either $\tilde{V}_{n}\left(m^{\prime}\right)>\tilde{V}_{n}(m)$ or $\tilde{V}_{n}\left(m^{\prime}\right)<\tilde{V}_{n}(m)$. The finding that $F_{2}$ does not first order stochastically dominate $F_{1}$ implies that $\tilde{V}_{n}(m)>\tilde{V}_{n}\left(m^{\prime}\right){ }^{5}$

Obviously $F_{2}$ may not first order stochastically dominate $F_{1}$ due to a variety of features of the two distribution functions. My model specification places restrictions on the way in which FOSD can fail. In particular, if $F_{2}$ does not FOSD $F_{1}$, there must exist some $x^{*}$ such that $F_{2}(x) \leq F_{1}(x)$ for all $x \leq x^{*}$ and $F_{2}(x)>F_{1}(x)$ for all $x>x^{*}$. That is, the c.d.f.s should intersect either never (in which case $F_{2}$ first order stochastically dominates $F_{1}$ ) or once and only once (in the case of failure of FOSD). ${ }^{6}$ Multiple crossings of the c.d.f.s could be produced by sampling variability or model misspecification.

To illustrate some of my analytical results I extend the example using the uniform $G$ on the interval $[0,10]$. In Figure 3 I plot the equilibrium wage distributions for minimum wage values of $m \in\{6,7,8,9\}$ for values of the bargaining power parameter $\alpha \in\{.5, .7, .8, .9\}$. In the case of $\alpha=.5$ (Figure 3.a), the value of search increases when moving from $m=6$ to $m=7$, and the equilibrium wage distribution at $m=7$ first order stochastically dominates the one associated with $m=6$ as must be the case from Corollary 3. However, though the value of search decreases when $m$ moves from 7 to 8 and 9 , these (degenerate) wage distributions first order stochastically dominate the one associated with $m=7$. Thus, from the observation that one wage distribution first order stochastically dominates another, we cannot generally conclude that welfare has increased using my welfare criterion, which is consistent with the analytic results presented above.

The remaining panels of Figure 3 demonstrate that minimum wage increases do not necessarily lead to new wage distributions which stochastically dominate the original ones. I have

\footnotetext{
${ }^{5}$ Note that $F_{1}$ can never FOSD $F_{2}$ for the simple reason that $F_{1}(w)>0$ and $F_{2}(w)=0$ for all $w \in\left[m, m^{\prime}\right)$.

${ }^{6}$ The single-crossing property is not sufficient to produce second order stochastic dominance.
} 
chosen high values of $\alpha$ to illustrate this point, since when $\alpha$ is high, minimum wage increases will in general lead to reductions in the value of search. This point is best illustrated in Figure 3.c, corresponding to the case of $\alpha=.8$. The wage distribution associated with $m=9$ does not stochastically dominate any of the other minimum wage distributions, the reason being the relatively low search value associated with $m=9$. Observations of this failure of FOSD would have led us to correctly infer that there had been a reduction in welfare.

As these results and illustrations make clear, it is difficult to assess welfare impacts from changes in wage distributions. I now turn to another characteristic of the relationship between the pre- and post-change wage distributions that may have some informational value and to which it is possible to give a reasonably intuitive and yet precise definition connected with the notion of spillover.

\subsection{Results Using Conditional Wage Distributions}

Consider a wage rate $w$ such that $w>m^{\prime}>m$. Then under either value of the minimum wage the density of accepted wages at $w$ exists. $^{7}$ Consider the ratio of the density at $w$ under $m^{\prime}$ and $m$, which is in essence a likelihood ratio. Then I define

$$
\begin{aligned}
L\left(w ; m, m^{\prime}\right) & =\frac{\frac{\alpha^{-1} g\left(\tilde{\theta}\left(w, \tilde{V}_{n}\left(m^{\prime}\right)\right)\right)}{\tilde{G}\left(m^{\prime}\right)}}{\frac{\alpha^{-1} g\left(\tilde{\theta}\left(w, \tilde{V}_{n}(m)\right)\right)}{\tilde{G}(m)}} \\
& =\frac{\tilde{G}(m) \times g\left(\tilde{\theta}\left(w, \tilde{V}_{n}\left(m^{\prime}\right)\right)\right)}{\tilde{G}\left(m^{\prime}\right) \times g\left(\tilde{\theta}\left(w, \tilde{V}_{n}(m)\right)\right)} .
\end{aligned}
$$

The ratio $\tilde{G}(m) / \tilde{G}\left(m^{\prime}\right)$ in $L\left(w ; m, m^{\prime}\right)$ can be referred to as the truncation effect of the minimum wage change. Since $\tilde{G}(m)>\tilde{G}\left(m^{\prime}\right)$, this effect is always greater than 1 and is

\footnotetext{
${ }^{7}$ For purposes of this discussion we assume that the matching distribution has unbounded support, which implies that the wage distribution will share this characteristic as well whenever $\alpha>0$.
} 
independent of the value of $w, w>m^{\prime}$; I will write it as $T\left(m, m^{\prime}\right)$. This effect on the ratio of wage densities at $w$ is viewed as rather mechanical and uninteresting. Instead, what I will refer to as the spillover effect is the term

$$
S\left(w ; m, m^{\prime}\right)=\frac{g\left(\tilde{\theta}\left(w, \tilde{V}_{n}\left(m^{\prime}\right)\right)\right)}{g\left(\tilde{\theta}\left(w, \tilde{V}_{n}(m)\right)\right)} .
$$

In this way we have constructed a decomposition of the likelihood ratio of the wage density at $w$ before and after the wage change, which is

$$
L\left(w ; m, m^{\prime}\right)=T\left(m, m^{\prime}\right) S\left(w ; m, m^{\prime}\right) .
$$

It will be convenient to work with an additive decomposition of the log likelihood ratio, or

$$
\ln L\left(w ; m, m^{\prime}\right)=\ln T\left(m, m^{\prime}\right)+\ln S\left(w ; m, m^{\prime}\right)
$$

Using the logarithmic decomposition, it is clear that the truncation effect shifts $\ln L$ by the uniform amount $\ln T\left(m, m^{\prime}\right)$. Furthermore we know that $\ln T\left(m \cdot m^{\prime}\right)>0$ for any two binding minimum wages $m^{\prime}>m$. Our main interest is in the manner in which the shape of the wage density above $m^{\prime}$ changes with a change in the minimum wage. I will assess this by looking at the manner in which $\ln L\left(w ; m, m^{\prime}\right)$ varies in $w$. That is, we are interested in

$$
\frac{\partial \ln L\left(w ; m, m^{\prime}\right)}{\partial w}=\frac{\partial \ln S\left(w ; m, m^{\prime}\right)}{\partial w} .
$$

I work with the logarithm of the likelihood ratio so that the truncation effect can be ignored. 
Definition 5 The quantity $\partial \ln S\left(w ; m, m^{\prime}\right) / \partial w$ is called the shape perturbation at $w$ associated with the minimum wage increase from $m$ to $m^{\prime}$. We denote this quantity by $S P\left(w ; m, m^{\prime}\right)$.

In general, minimum wage changes result in changes in the shape of the density above the new minimum wage. It is interesting to consider when this would not be the case. I begin with one readily checkable sufficient condition for the absence of shape perturbations.

Proposition 6 Assume that $G(\theta)$ is continuously differentiable on its support $Q \subseteq R_{+}$, where $Q$ is a connected set. Then there is no spillover when moving from minimum wage $m$ to $m^{\prime}$ if and only if at least one of the following:

1. $\tilde{V}_{n}\left(m^{\prime}\right)=\tilde{V}_{n}(m)$

2. $g(\theta)=\tau^{-1} \exp (\beta \theta)$ for all $\theta \in Q$, where $\tau=\tau(\beta, Q)=\int_{Q} \exp (\beta x) d x<\infty$.

Proof. For $S P\left(w ; m, m^{\prime}\right)$ to be 0 for all $w$ requires that $S\left(w ; m, m^{\prime}\right)$ be independent of $w$ for all $w>m^{\prime}$, or

$$
\begin{aligned}
S\left(w ; m, m^{\prime}\right) & =\frac{g\left(\frac{w}{\alpha}-\frac{1-\alpha}{\alpha} \rho \tilde{V}_{n}\left(m^{\prime}\right)\right)}{g\left(\frac{w}{\alpha}-\frac{1-\alpha}{\alpha} \rho \tilde{V}_{n}(m)\right)} \\
& =k \forall w>m^{\prime} .
\end{aligned}
$$

If $\tilde{V}_{n}\left(m^{\prime}\right)=\tilde{V}_{n}(m)$, then $S\left(w ; m, m^{\prime}\right)=1$ for all $w>m^{\prime}$, so condition 1 is obvious.

Rewrite $S\left(w ; m, m^{\prime}\right)$ as $g(y+b) / g(y+a)$. This expression is independent of $y$ for all values of $y$ if and only if $g(x+y)=\tau g(x) g(y)$ for all values of $x$ and $y$ such that $g(x+y), g(x)$, and $g(y)$ are well-defined and non-zero. After rewriting

$$
g(x)=\exp (r(x))
$$


the condition $g(x+y)=\tau g(x) g(y)$ implies

$$
r(x+y)=\ln \tau+r(x)+r(y)
$$

which for continuous $r$ is equivalent to

$$
r(x)=-\ln \tau+\beta x
$$

for some $\beta$. Then

$$
g(x)=\tau^{-1} \exp (\beta x)
$$

where $\tau$ is a constant selected such that $\tau=\int_{Q} \exp (\beta x) d x .^{8}$

In what follows, when looking for "spillover effects" I will be focusing primarily on whether condition 2 in the above proposition is satisfied, since it is the only "global" one of the two. By this I mean that satisfaction of condition 2 does not depend on the particular values of $m$ and $m^{\prime}$ chosen, so long as they are both binding minimum wages.

The types of distributions which satisfy condition 2 are relatively familiar ones. When $\beta=0$, then we have $g(x)=\tau^{-1}$ on $Q$, which implies that $Q$ is a finite interval $[\underline{\theta}, \bar{\theta}]$, with $0 \leq \theta<\theta<\infty$, so that $\tau=[\bar{\theta}-\underline{\theta}]$. In this case $G$ corresponds to a uniform distribution. When $\beta<0$, we have the case of a negative exponential distribution. When $Q=R_{+}$, then $\tau=|\beta|^{-1}$. When $Q$ is a proper subset of $R_{+}$, then $g$ is a truncated negative exponential density. Finally, when $\beta>0$, for integrability of the density, $Q$ must be a proper subset of $R_{+}$. In other analytic

\footnotetext{
${ }^{8}$ I am very much indebted to Bernard Selanié for suggesting this method of proof.
} 
respects this case closely resembles that of $\beta<0$.

The power of Proposition 6 lies in its demonstration that these distributions are the only ones in the class of distributions considered that cannot exhibit "spillover" for any values of $m$ and $m^{\prime}$. Furthermore, the negative exponential distribution is the only one that cannot exhibit spillover if our attention is restricted to distributions whose support is $R_{+}$.

A result which follows immediately from condition 2 of the above proposition that we shall make use of in the sequel is the following corollary.

Corollary 7 If condition 2 of Proposition 6 is satisfied, then

$$
f(w ; m)=\delta\left(m, m^{\prime}\right) f\left(w ; m^{\prime}\right), \forall w>m^{\prime}>m,
$$

where

$$
\delta\left(m, m^{\prime}\right)=\frac{\tilde{G}\left(m^{\prime}\right)}{\tilde{G}(m)} \frac{g\left(-\frac{1-\alpha}{\alpha} \rho \tilde{V}_{n}(m)\right)}{g\left(-\frac{1-\alpha}{\alpha} \rho \tilde{V}_{n}\left(m^{\prime}\right)\right)} .
$$

I now develop a test for what I have defined above as spillover effects that does not require an assumption of any particular functional form for $G$, and in fact does not make much use of the model structure. In this sense, this can be considered a general test for whether a minimum wage change results in shape perturbation effects. It is important to keep in mind that the absence of shape perturbation effects does not imply that there are no general welfare effects of minimum wage changes in the population. I will illustrate this point below with the use of some simulations.

The test I develop is a straightforward extension of the general family of nonparametric tests which test whether two population distributions are equal over the entire (common) support 
of the distributions. Let $F_{1}(X)$ denote the cumulative distribution function of the random variable $X$ and let $F_{2}(Y)$ denote the c.d.f. of the random variable $Y$. Let the common support of the two distributions be denoted by $\Omega$. There exist several nonparametric tests of the null hypothesis: $H_{0}: F_{1}(x)=F_{2}(x), \forall x \in \Omega$; well-known examples are the Kolmogorov-Smirnov Two Sample Test and the Wald-Wolfowitz Runs Test.

I propose to test proportionality of the population wage densities after a minimum wage change over a subset of the support of the wage distribution. I employ the following result.

Proposition 8 Let $f_{1}(w)=\delta f_{2}(w)$ for all $w \in S \subset \Omega$, where $S$ is a connected set strictly contained in $\Omega$, with $S=(a, b)$. Then $F_{1}(w \mid w \in S)=F_{2}(w \mid w \in S)$.

Proof. The conditional c.d.f. $F_{k}(w \mid w \in S)$ is given by

$$
F_{k}(w \mid w \in S)=\frac{\int_{a}^{w} f_{k}(x) d x}{\int_{a}^{b} f_{k}(x) d x}, k=1,2, w \in S
$$

Since $f_{1}(w)=\delta f_{2}(w)$ for $w \in S$,

$$
\begin{aligned}
F_{1}(w \mid w \in S) & =\frac{\int_{a}^{w} \delta f_{2}(x) d x}{\int_{a}^{b} \delta f_{2}(x) d x} \\
& =F_{2}(w \mid w \in S), \forall w \in S .
\end{aligned}
$$

To implement the test for shape perturbation requires that I restrict attention to the subset of wages from the two minimum wage regimes that are greater than the largest minimum wage. Let $m^{\prime}$ denote the higher of the two (binding) minimum wages and $m$ the lesser of the two. I have access to $n_{1}$ wage observations which are greater than $m^{\prime}$ from the regime when $m$ is in 
force, where the draws are denoted $w_{1}^{1}, w_{2}^{1}, \ldots, w_{n_{1}}^{1}$, and we have access to $n_{2}$ wage observations all of which are greater than $m^{\prime}$ when the regime $m^{\prime}$ is in place, with the wage observations given by $w_{1}^{2}, w_{2}^{2}, \ldots, w_{n_{2}}^{2}$. The null hypothesis that to be tested is that

$$
H_{0}: F_{1}\left(w \mid w>m^{\prime}\right)=F_{2}\left(w \mid w>m^{\prime}\right), \forall w>m^{\prime} .
$$

Now a consistent estimator of the conditional c.d.f.s is given by

$$
\hat{F}_{k}\left(w \mid w>m^{\prime}\right)=n_{k}^{-1} \sum_{i=1}^{n_{k}} \chi\left[w_{i}^{k} \leq w\right], \forall w>m^{\prime}
$$

where $\chi[A]$ is the indicator function which takes the value 1 when $A$ is true and is 0 otherwise. I will employ the Kolmogorov-Smirnov Two Sample Test to test [11], which is based on the maximum distance between the two empirical (conditional) cumulative distribution functions. In our case the test statistic is defined as

$$
D_{n_{1}, n_{2}}=\max _{w>m^{\prime}}\left|\hat{F}_{1}\left(w \mid w>m^{\prime}\right)-\hat{F}_{2}\left(w \mid w>m^{\prime}\right)\right|
$$

The "degrees of freedom" for the two-sample test are given by $\sqrt{\frac{n_{1} \times n_{2}}{n_{1}+n_{2}}}$. Using this value, critical values for $D_{n_{1}, n_{2}}$ are the same as for the one-sample version of the test and are readily available. ${ }^{9}$

\subsection{Results Using Matched Data}

By matched data we mean observations on the same individuals under (at least) two different minimum wage regimes. A number of researchers have examined the impact of minimum wage changes on labor market outcomes using panel data, ${ }^{10}$ though none have attempted to

\footnotetext{
${ }^{9}$ See Rao (1973), pp. 420-422, for a brief discussion of these results.

${ }^{10}$ See, for example, Egge et al. (1970), Linneman (1982), Smith and Vavrichek (1992), and Currie and Fallick
} 
assess welfare effects per se from such data. Given the assumptions of the model, it is trivial to learn the welfare effect of a minimum wage given access to wage information for at least one individual who was paid more than the minimum wage in each year. Let there exist a set of individuals in the population $I$ who remained at the same employer both before and after the minimum wage changed and who have a wage rate greater than the (respective) minimum in both years. Let $i$ be a member of this set, and let their pre- and post-minimum wage change wage observations be denoted by $w_{i}$ and $w_{i}^{\prime}$. Then

$$
\begin{aligned}
& w_{i}=\alpha \theta_{i}+(1-\alpha) \rho V_{n}(m), \theta_{i}>\hat{\theta}\left(m, \tilde{V}_{n}(m)\right) \\
& w_{i}^{\prime}=\alpha \theta_{i}+(1-\alpha) \rho V_{n}\left(m^{\prime}\right), \theta_{i}>\hat{\theta}\left(m^{\prime}, \tilde{V}_{n}\left(m^{\prime}\right)\right)
\end{aligned}
$$

so that

$$
w_{i}^{\prime}-w_{i}=\rho(1-\alpha)\left\{\tilde{V}_{n}\left(m^{\prime}\right)-\tilde{V}_{n}(m)\right\}
$$

The following result is immediate.

Proposition 9 The minimum wage change was welfare improving if and only if $E\left(w^{\prime}-w \mid w>m, w^{\prime}>m^{\prime}\right)>0$.

Proof. According to [12] the wage difference for any $i \in I$ is equal to $\rho(1-\alpha)\left\{\tilde{V}_{n}\left(m^{\prime}\right)-\tilde{V}_{n}(m)\right\}$, which is independent of $i$, so that the expectation over the set $I$, or any subset of $I$, is equal to this constant. The constant is only positive if and only if $\tilde{V}_{n}\left(m^{\prime}\right)-\tilde{V}_{n}(m)>0$.

Because the constant is the same for all members of $I$, the following strong implication (1996). 
emerges.

Corollary 10 The wage differences $\left(w_{i}^{\prime}-w_{i}\right)=\left(w_{j}^{\prime}-w_{j}\right)$, for all $i, j \in I$.

This result implies that the variance in wage changes over the set $I$, or any subset of $I$, is 0 , which is clearly something we don't expect to see in any actual data set. We shall discuss this issue further below when we carry out the empirical exercise.

It is obvious that there are many reasons to expect increases in the average wage paid to job stayers [those paid more than the minimum wage in this case] that are unrelated to changes in the nominal minimum wage. However, it is the case that the model places an additional restriction on the magnitude of the increase in the average wage for our reference group that can result solely from a change in the statuatory minimum wage. This restriction is developed in the following two results.

Proposition 11 Let $m$ be a binding minimum wage. Then

$$
\frac{d \rho V_{n}(m ; \Psi)}{d m} \leq 1
$$

Proof. Let $x \equiv \rho \tilde{V}_{n}(m)$. Then the implicit reservation wage under a binding minimum wage $m$ is the solution to

$$
0=x-b-k\left\{(G(\hat{\theta})-G(m))(m-x)+\alpha \int_{\hat{\theta}}(\theta-x) d G(\theta)\right\}
$$

where $k \equiv \lambda /(\rho+\eta)$ and $\hat{\theta}=(m-(1-\alpha) x) / \alpha$. Then implicitly differentiating [13] delivers

$$
\frac{d x}{d m}=\frac{k(G(\hat{\theta})-G(m))-k g(m)(m-x)}{1+k(G(\hat{\theta})-G(m))+k \alpha(1-G(\hat{\theta}))} .
$$


Since $\hat{\theta}>m$, all terms in the denominator are positive or nonnegative. Since $m-x \leq 0$, the numerator is less than or equal to $k(G(\hat{\theta})-G(m))$.

Corollary 12 Let $m$ and $m^{\prime}$ be two binding minimum wages in the labor market environment $\Psi$, with $m<m^{\prime}<\infty$. For an individual at the same job under $m$ and $m^{\prime}$, and for whom $w>m$ and $w^{\prime}>m^{\prime}$

$$
w^{\prime}-w \leq m^{\prime}-m
$$

Proof. An individual at the same job [i.e., the same $\theta$ ] is paid $w^{\prime}=\alpha \theta+(1-\alpha) \rho V_{n}\left(m^{\prime} ; \Psi\right)$ under $m^{\prime}$ and $w=\alpha \theta+(1-\alpha) \rho V_{n}(m ; \Psi)$ under $m$, so that

$$
w^{\prime}-w=(1-\alpha) \rho\left(V_{n}\left(m^{\prime} ; \Psi\right)-V_{n}(m ; \Psi)\right), w>m, w^{\prime}>m^{\prime}
$$

By Proposition $11 \rho\left(V_{n}\left(m^{\prime} ; \Psi\right)-V_{n}(m ; \Psi)\right) \leq m^{\prime}-m$, and the result follows since $(1-\alpha) \leq 1$.

Since the data I use below spans a minimum wage increase of 40 cents, by Corollary 12 we should not observe a change in the wages of job stayers (paid more than the minimum wage in both periods) of more than $\$ .40$ [and this is the upper bound corresponding to the case of $\alpha=0$ ]. Thus the model places strong restrictions on both the magnitude of the change in the average wage of job stayers and the variance of wage changes within this group of individuals.

Unfortunately, the data used in the empirical exercise do not allow me to match individuals in the periods before and after the minimum wage change with absolute certainty. Notwithstanding these matching problems, there is the additional task of determining whether the individual has the same job in March 1998 she had in March 1997. Since there will be 
substantial scope for misclassifying employed individuals in terms of their membership in population $I$, it is worthwhile to determine the effect of the minimum wage on the mean and standard deviation of wage changes in the population of individuals who changed jobs and who were paid more than the minimum wage in each period. I define as population $I^{\prime}$ all individuals with $w>m, w^{\prime}>m^{\prime}$, and $\theta \neq \theta^{\prime}$. The mean wage change under these selection rules is given by

$$
\begin{gathered}
E\left(w^{\prime}-w \mid w^{\prime}>m^{\prime}, w>m, \theta^{\prime} \neq \theta\right)=\rho(1-\alpha)\left\{\tilde{V}_{n}\left(m^{\prime}\right)-\tilde{V}_{n}(m)\right\} \\
+\alpha\left\{E\left(\theta^{\prime} \mid \theta^{\prime}>\hat{\theta}\left(m^{\prime}, \rho \tilde{V}_{n}\left(m^{\prime}\right)\right)\right)-E\left(\theta \mid \theta>\hat{\theta}\left(m, \rho \tilde{V}_{n}(m)\right)\right)\right\},
\end{gathered}
$$

where I have used the fact that $E\left(\theta^{\prime} \mid \theta^{\prime}>a, \theta>b\right)=E\left(\theta^{\prime} \mid \theta^{\prime}>a\right)$ and $E\left(\theta \mid \theta^{\prime}>a, \theta>b\right)=E(\theta \mid \theta>b)$ under the model. ${ }^{11}$ Since $E(\omega \mid \omega>a)$ is a nondecreasing function of $a$, there are not any strong implications we can derive for the mean wage change in the population $I^{\prime}$ because the lower truncation point $\hat{\theta}$ depends both on $m$ and $\tilde{V}_{n}(m)$. To show this, observe that

$$
\begin{aligned}
& E\left(\theta^{\prime} \mid \theta^{\prime}>\hat{\theta}\left(m^{\prime}, \rho \tilde{V}_{n}\left(m^{\prime}\right)\right)\right)-E\left(\theta \mid \theta>\hat{\theta}\left(m, \rho \tilde{V}_{n}(m)\right)\right) \\
= & \tilde{G}\left(\hat{\theta}\left(m^{\prime}, \rho \tilde{V}_{n}\left(m^{\prime}\right)\right)\right)^{-1} \int_{\hat{\theta}\left(m^{\prime}, \rho \tilde{V}_{n}\left(m^{\prime}\right)\right)} \theta d G(\theta) \\
& -\tilde{G}\left(\hat{\theta}\left(m, \rho \tilde{V}_{n}(m)\right)\right)^{-1} \int_{\hat{\theta}\left(m, \rho \tilde{V}_{n}(m)\right)} \theta d G(\theta) \gtreqless 0 \\
\Leftrightarrow & \hat{\theta}\left(m^{\prime}, \rho \tilde{V}_{n}\left(m^{\prime}\right)\right) \gtreqless \hat{\theta}\left(m, \rho \tilde{V}_{n}(m)\right) .
\end{aligned}
$$

\footnotetext{
${ }^{11}$ This independence property of the conditional expectation functions would not hold if on-the-job search were allowed, for example.
} 
Now

$$
\begin{aligned}
\hat{\theta}\left(m^{\prime}, \rho \tilde{V}_{n}\left(m^{\prime}\right)\right) & >\hat{\theta}\left(m, \rho \tilde{V}_{n}(m)\right) \\
& \Leftrightarrow m^{\prime}-m>\rho(1-\alpha)\left\{\tilde{V}_{n}\left(m^{\prime}\right)-\tilde{V}_{n}(m)\right\} .
\end{aligned}
$$

Equation [15] shows the source of the ambiguity. Say that welfare decreases after the minimum wage change. In this case, $\hat{\theta}\left(m^{\prime}, \rho \tilde{V}_{n}\left(m^{\prime}\right)\right)>\hat{\theta}\left(m, \rho \tilde{V}_{n}(m)\right)$ so that $E\left(\theta^{\prime} \mid \theta^{\prime}>\hat{\theta}\left(m^{\prime}, \rho \tilde{V}_{n}\left(m^{\prime}\right)\right)\right)$ $-E\left(\theta \mid \theta>\hat{\theta}\left(m, \rho \tilde{V}_{n}(m)\right)\right)>0$ and [14] has an indeterminate sign. On the other hand, when the minimum wage has a positive effect on welfare, then the inequality in [15] may not be satisfied; as a result $E\left(\theta^{\prime} \mid \theta^{\prime}>\hat{\theta}\left(m^{\prime}, \rho \tilde{V}_{n}\left(m^{\prime}\right)\right)\right)-E\left(\theta \mid \theta>\hat{\theta}\left(m, \rho \tilde{V}_{n}(m)\right)\right)$ has an indeterminate sign and therefore so has the entire expression [14]. Thus the mean wage change in the population $I^{\prime}$ cannot be used to infer welfare effects without additional information.

Another important difference between the distributions of wage changes in the populations $I$ and $I^{\prime}$ is in their respective variances. As I have noted above, the variance of $w^{\prime}-w$ is 0 in $I$, while in $I^{\prime}$ it is strictly positive as long as $G$ is nondegenerate. I will refer to this result when attempting to interpret the empirical results below that were obtained using a matched sample.

\section{Illustrations}

Before proceeding to the empirical example I will illustrate a number of the results derived in the previous section by conducting some small simulation exercises. In conducting these exercises I will continue to use the value of search given a minimum wage of $m$ as the welfare measure. The simulation looks at the cross-sectional wage distribution when all agents in the population are identical, in the sense of inhabiting the same labor market environment $(\Psi)$. I performed the exercise once under the assumption that the matching distribution was negative 
exponential and the other time under the assumption that the $G$ was log normal. Since the density of the negative exponential has the separability property given in Proposition 6 (condition 2), there will be no spillovers produced by minimum wage changes. Since the log normal density does not have this property, spillover effects of minimum wage changes generally will be observed in this case. The parameter values assumed for the labor market environment in the two cases are:

\section{Distribution}

\section{Parameter Exponential Log Normal}

\begin{tabular}{|c|c|c|}
\hline$\lambda$ & .2 & .2 \\
\hline$\eta$ & .05 & .05 \\
\hline$\rho$ & .003 & .003 \\
\hline$b$ & 0 & 0 \\
\hline$\alpha$ & .35 & .35 \\
\hline$\mu$ & .2 & 1.2 \\
\hline$\sigma$ & - & 1 \\
\hline
\end{tabular}

where under the exponential assumption, $g(\theta ; \mu)=\mu \exp (-\mu \theta)$ and under the log normal assumption, $g(\theta ; \mu, \sigma)=(2 \pi)^{-.5}(\theta \sigma)^{-1} \exp \left(-\frac{1}{2}\left(\frac{\ln (\theta)-\mu}{\sigma}\right)^{2}\right)$. Most of the parameter values are similar to those obtained in initial attempts to estimate the equilibrium model using CPS data as reported in Flinn (1999). The flow parameters should be thought of as measured in monthly units; thus the assumption that $\lambda=.2$ implies that the average duration between job offers to an unemployed searcher is 5 months and the dissolution rate of .05 implies that jobs last 20 months on average.

I assume that the current minimum wage is 5 , which is a binding minimum wage under 
both distributional assumptions. Under the log normal distributional assumption, the welfare value associated with $m=5$ is equal to 3.704 , while under the exponential it is 3.474 [note that it is not meaningful to compare these two values]. Since the minimum wage is binding in both cases, the observed wage distribution will have a spike at 5 . This is illustrated in the plots of the respective c.d.f.s in Figures 4.a and 4.b.

I now consider the impact of imposing one of two alternative minimum wages on the labor market [where the labor market is summarized by the table of values above]. The first alternative consists of raising the minimum wage by 50 percent, to 7.50 , while the second is an even more radical change of 100 percent, to 10.00 . The welfare values associated with each of the six cases considered is

\begin{tabular}{|c|c|c|}
\multicolumn{1}{c}{} & \multicolumn{2}{c}{ Distribution } \\
\cline { 2 - 3 }$m$ & Exponential & Log Normal \\
\hline 5.00 & 3.474 & 3.704 \\
\hline 7.50 & 3.604 & 3.789 \\
\hline 10.00 & 3.418 & 3.658 \\
\hline
\end{tabular}

I have deliberately chosen parameter values and minimum wage rates so as to attain the result that while a minimum wage change to 7.50 is beneficial under either distributional assumption, an increase to 10.00 results in a lower level of welfare than under the status quo of 5.00.

The plots of the wage c.d.f.s under the alternative minimum wage levels are presented in Figures 4.c-4.f. As we know from the model structure, the spikes at the minimum wage become progressively greater as the minimum wage is increased. However, it is clear that the underlying welfare level is not monotonically increasing in the size of the spike, so this is not a useful criteria 
for judging the benevolence of a minimum wage change.

I have graphed the differences in the cumulative wage distributions associated with the proposed new minimum wages of 7.50 and 10.00 and that associated with the current minimum wage of 5.00 in Figure 5. In all four panels the new wage offer distribution stochastically dominates the old one. Welfare is in fact only increased in two of the four cases, however.

Figure 6 contains ratios of the conditional c.d.f.s associated with the two proposed new minimum wages to the conditional c.d.f. associated with the baseline minimum wage under both distributional assumptions. Figures $6 . \mathrm{b}$ and $6 . \mathrm{d}$ correspond to the negative exponential case. The equality of the conditional distributions under this distributional follows from the analytic results above. The important point to note in this case is that the absence of spillover, as I have formally defined it, does not indicate the absence of welfare effects in the population at large. In the case represented in Figure 6.b, although there was no spillover when moving from $m=5$ to $m=7.50$ there was a positive welfare gain. Conversely, the case of no spillover represented in Figure 6.d corresponded to a worsening of the welfare of population members. The lesson from this is that when the conditions of Proposition 6 are satisfied, changes in the conditional wage distributions cannot reveal anything about changes in the value of unemployed search..

Under the log normality assumption, we know from Proposition 6 that the conditional c.d.f.s will only be proportional if the values of search under the different minimum wages are the same, which they are not. Figures 6.a and 6.c confirm the fact that spillover exists in this case. The following interesting result should also be noted. The graph in Figure 6.a plots the ratio:

$$
\frac{F_{2}\left(w \mid w>m^{\prime}\right)}{F_{1}\left(w \mid w>m^{\prime}\right)}
$$


where the conditional cumulative distribution function in the numerator corresponds to the regime in which the minimum wage is set at 7.50 and the conditional c.d.f. in the denominator corresponds to the regime in which the minimum wage is set at 5.00. The fact that this ratio is monotonically decreasing from a value greater than 1 and asymptotically approaching 1 from above indicates that the conditional c.d.f. associated with $m=5$ first order stochastically dominates the conditional c.d.f. associated with $m=7.50$. Though one might interpret this result to imply that the conditional wage offer distribution associated with $m=5$ is "better" than the one associated with $m=7.50$, this is not the case. Figure 6.c demonstrates the converse result. In that case, the conditional wage distribution associated with $m=10$ first order stochastically dominates the one associated with $m=5$; however, the welfare level associated with the "dominated" conditional wage distribution is higher.

\section{DATA AND Empirical Exercises}

The data for my empirical example are drawn from the March 1997 and 1998 Current Population Survey (CPS) samples. I have selected these two periods because they span a change in minimum wage law. In March 1997 , the national minimum wage was $\$ 4.75$ an hour, having been changed from $\$ 4.25$ on October 1, 1996. At the time of the March 1997 interviews, the minimum wage of $\$ 4.75$ had been in effect for approximately 6 months. On September 1, 1997, the minimum wage of $\$ 4.75$ was increased to $\$ 5.15$. Thus at the time of the March 1998 CPS interviews, the new minimum wage had been in effect for approximately 7 months.

As is true of the empirical analysis performed in Flinn (1999), I focus attention on labor market participants between the ages of 16 and 24, inclusive. This age group has by far the largest proportion of employed members paid exactly at or within a few cents of the minimum wage. If the minimum wage is to have a substantial impact on the labor market outcomes and 
welfare of any particular group in the population, it is most likely to be this one.

The CPS is a household survey of addresses which has the structure of a rotating panel. Dwelling units are selected to be in the survey for 4 consecutive months, then are out of the sample for 8 months, and then finally return for 4 consecutive months. Detailed information concerning each household member's current job, if they are employed at the time of the monthly survey, is only obtained from individuals in their 4th and 8th month of participation in the sample. Thus I have selected individuals for inclusion in the sample who at the time of the March interview were (1) between 16 and 24 years old, (2) were in the 4th or 8th month of survey participation, and (3) reported themselves to be currently working or searching for a job. We have not excluded individuals who reported being enrolled in school full-time since this group accounts for a substantial proportion of employees paid the minimum wage.

A few characteristics of the CPS data and U.S. minimum wage laws complicate any empirical analysis on this issue, even one as simple and descriptive as that carried out here. First, the minimum wage is set in terms of hourly compensation rates, though many employees are not paid on an hourly basis. Employed individuals in the Outgoing Rotation Groups (i.e., those in their 4th or 8th month of survey participation) are asked whether they are paid on an hourly basis. If they respond that they are paid on that basis, they are asked to report their hourly rate. All employed individuals in the ORG are also asked their gross weekly earnings and their usual weekly hours of work. For individuals paid on an hourly basis, their hourly wage report is used as a measure of their wage rate. For employed individuals who do not report an hourly wage, I attempt to infer one by using the standard procedure of dividing the gross weekly wage by their reported usual hours of work. ${ }^{12}$ Since individuals whose wages are inferred from their report of

\footnotetext{
${ }^{12}$ This procedure fails when usual weekly hours are not reported, which they are not when individuals report that
} 
gross weekly wages and usual hours are likely to have a noisier measure of their "true" rate of hourly compensation, they are less likely to be clustered tightly around or exactly at the prevailing minimum wage, even when that is their true "target" hourly compensation rate. This problem provides another rationale for focusing attention on young labor market participants, since they are much more likely to be paid on an hourly basis than are older workers. ${ }^{13}$

The second important issue with the CPS data is that of proxy respondents. When CPS interviewers contact a household, one individual in the household provides all the information for each person living in it. This person is often the head of the household or the spouse of the head. Since many minimum wage workers live as dependents in someone else's household, often their parents', the measurement problems we referred to in the previous paragraph are likely to be exacerbated. While these measurement problems significantly reduce the appeal of the CPS, it remains the best large-scale and representative survey of the U.S. population for studying minimum wage effects on labor market outcomes.

In the second stage of the empirical analysis, I construct an "event study" that attempts to determine whether there were any discernible effects of the minimum wage change between March 1997 and March 1998 on the labor market status of individuals who appear in both samples. Since the CPS does not provide unique individual-level identifiers that would allow researchers to match individuals across years in a straightforward manner, a more circuitous procedure must be used. I begin by matching household identification numbers across March 1997 and March 1998; the household identifier is unique so that errors in matching introduced at this stage should be almost nonexistent. The person matching is performed as follows. When a

they have no set weekly work schedule.

${ }^{13}$ In the 1997 March CPS sample I have drawn, 83.7 percent of employed individuals report being paid on an hourly basis, while in the 1998 March CPS sample the corresponding percentage is 84.1 
household-level match is found between the two years, for each individual in the household in 1997

I determine whether there is anyone in the same household in 1998 who is (1) of the same sex and (2) 0 to 2 years older. If any individual in the 1998 household satisfies these two conditions, they are considered to be the same person. Of course, the presence of same-sex twins, for example, will cause problems, but it is likely that the success rate of this matching procedure is quite high.

\subsection{Cross-Sectional Wage Distributions}

I begin by presenting histograms of cross-sectional wages for the unmatched sample in March 1997 and March 1998, which are contained in Figure $7 .{ }^{14}$ In each figure, vertical lines are drawn at the wage rates 4.75 and 5.15 for reference purposes. One feature of both of the figures that is immediately apparent is the large number of spikes. These spikes tend to occur both at the minimum wage (i.e., 4.75 in 1997 and 5.15 in 1998) and at other points that are likely to be the result of reporting error. By way of illustration, the following small table shows the proportion of each sample that gives a wage report exactly equal to one of five possible values.

\begin{tabular}{|c|c|c|}
\multicolumn{1}{c}{} & \multicolumn{2}{c}{ Proportion } \\
\cline { 2 - 3 } Wage Rate & $\mathbf{1 9 9 7}$ & $\mathbf{1 9 9 8}$ \\
\hline 4.75 & .061 & .006 \\
\hline 5.00 & .114 & .053 \\
\hline 5.15 & .003 & .060 \\
\hline 6.00 & .083 & .100 \\
\hline 7.00 & .057 & .084 \\
\hline
\end{tabular}

\footnotetext{
${ }^{14}$ I do not use any "smoothers" on these histograms by choice. Since the model underlying my analysis is predicated on the wage distribution not being everywhere continuous, the use of such devices would not be consistent with the theory, hence my criticism of the continuity assumptions utilized in Dinardo et al. (1996).
} 
The wage rate 5.00 is the modal value of the 1997 hourly wage distribution and the wage rate 6.00 is the modal value for 1998. In both cases, these happen to the integers immediately above the current minimum wage, but whether this is simply a coincidence is difficult to know. Even though I would claim that these results suggest the importance of rounding error in the data, it is important to note that the hourly rate of 4.75 is the third most commonly reported value in 1997 and 5.15 is the third most commonly reported value in 1998. I would argue that neither of these numbers, particularly 5.15, is a natural focal point for someone reporting a wage rate she is unsure of or wishes not to reveal. I take this as indirect evidence that the mass point at the minimum wage is a "real" one in both years. ${ }^{15}$

From the above table and the histogram, some shifts in the wage distribution between the two years are apparent. The mass point at the minimum wage in the two periods is essentially constant at 6 percent. In addition, there is some possible visual evidence that above the value 5.15 the distribution has shifted toward the right tail between the two years. I shall now rigorously examine this impression.

I begin by looking at the relationship between the empirical c.d.f.s in March 1997 and March 1998. From Corollary 4, we know that if $\hat{F}_{98}$ does not FOSD $\hat{F}_{97}$, then the increase in the minimum wage from $\$ 4.75$ to $\$ 5.15$ actually decreased welfare. To compute the relevant empirical c.d.f.s, I used all hourly wage observations from March 1997 that were greater than or equal to $\$ 4.75$ and all hourly wage observations from March 1998 that were greater than or equal to $\$ 5.15$. Figure 8.a contains the plots of the empirical c.d.f.s for the two years which were constructed from these wage observations, and Figure $8 . b$ contains the differences in the c.d.f.s [i.e., $\left.\hat{F}_{98}-\hat{F}_{97}\right]$. For

\footnotetext{
${ }^{15}$ For making such an argument possible, I am grateful to the U.S. Congress, which has chosen not to set the nonfarm or unified minimum wage at an integer value since 1975 (when the nonfarm minimum wage was $\$ 2.00$ for a 1-year period).
} 
all values of $w \geq 4.75, \hat{F}_{98} \leq \hat{F}_{97}$. Without conducting formal tests for FOSD, the evidence is relatively compelling for the presumption that the new wage distribution first order stochastically dominates the old. However, from this observation we cannot conclude that individuals on the supply side of the market were in fact better off in 1998 than they were in 1997.

Turning attention to the detection of spillover as a result of the new minimum wage, I use the Kolmogorov-Smirnov Two Sample Test after restricting both samples [1997 and 1998] to include only wage observations above the new minimum [which was 5.15 in this case]. The results are presented in Figure 9. The top panel presents graphs of the conditional c.d.f.s for the two years. There are notable differences between the two, which may be easier to view in the bottom panel where I plot $\hat{F}_{98}(w \mid w>5.15)-\hat{F}_{97}(w \mid w>5.15)$. If the differences were less than 0 for all values of $w>5.15$, then the conditional distribution of wages greater than 5.15 (or at least the estimate of it) would first order stochastically dominate the same distribution for 1997. While this is true for most values of $w>5.15$, it is not true for all. Therefore, a first order stochastic dominance relationship does not seem to hold, but it does seem that the conditional distribution in 1998 is more skewed toward higher values than is the 1997 conditional distribution.

I conducted a formal Kolmogorov-Smirnov test on the distributions as described above. The maximum distance between the two estimated conditional c.d.f.s is .0418 in absolute value. Given the large sample sizes of 1,061 and 1,393, the probability of obtaining a value of the test statistic of .055 is 5 percent under the null hypothesis of no difference in the conditional c.d.f.s. Therefore we conclude that there is no strong indication that the conditional distributions above the 1998 minimum wage changed in any systematic manner. ${ }^{16}$

\footnotetext{
${ }^{16}$ The test is not strictly appropriate since I have not constructed the two samples so as to ensure that the same individual does not appear in both samples. Since some individuals undoubtedly do belong to both the 1997 and 1998 samples, the assumption of independence is violated to some degree and the test results are biased, most likely in favor of the null hypothesis.
} 


\subsection{Empirical Analysis using the Matched CPS Sample}

In this section I use the matched CPS sample in an attempt to determine something about the welfare effect of the minimum wage change in September 1997. In describing the CPS data, I noted that it is not possible to be absolutely sure that individuals were accurately matched from the March 1997 and March 1998 samples, though the error rate should be small. More problematic for the utilization of the results which were derived in Section 3.3 is the inability to determine whether or not the individual is working at the same job in the two periods. This is primarily due to the fact that the CPS does not collect any information on the length of time individuals have been employed by their current employers. It is not possible to convincingly circumvent this problem, and our "solution" is admittedly problematic. Individuals will be considered to be at the same job in the two periods if the industrial and occupational classification of their job is the same in March 1997 and in March 1998. In determining whether they are the same, I use a relatively crude classification system that distinguishes between about 15 occupational and 20 industrial categories. I could have used three-digit occupation and industry codes, but I felt that reporting error, especially given the problem of proxy respondents, would have resulted in too few individuals classified as "stayers."

To make use of the analytic results from Section 3.3, attention is restricted to matched cases in which the individual is employed both in March 1997 and in March 1998 and is paid more than $\$ 4.75$ an hour in 1997 and more than $\$ 5.15$ an hour in 1998 . After imposing the matching and selection criteria, I was left with a total of 245 cases. Of these, 37.5 percent were classified as being in the same major industry and occupation groups in the two years. I will somewhat loosely refer to this group as "stayers," bearing in mind all the caveats which have been mentioned. A variety of moments of the sample wage distributions of movers and stayers are presented in Table 
1.

Using the result from Proposition 9, the positive mean wage change among the group of stayers implies that the minimum wage change had a positive welfare effect in the population. Of course, this interpretation relies heavily on the stationarity assumptions of the model, which are highly questionable particularly given the youth of the sample. However, it is interesting to note that the mean wage change is greater for stayers than for movers, a result not always found in research on mobility and wage determination. ${ }^{17}$ As was discussed in Section 3.3, if the welfare of individuals did increase after the minimum wage change, the mean wage difference of the movers could be of any sign, so the fact that it is positive but smaller than that of the stayers is not particularly informative for our purposes.

Though the positive sign of the mean wage change for the reference group is positive, the size of the increase is not consistent with the implication of the model that is given in Corollary 12. The increase of approximately 1 dollar in the mean wage of job stayers is over 250 percent greater than the upper bound on the change implied by the model.

Not surprisingly, the implication of Corollary 10 [i.e., no variance in wage changes among stayers] is clearly refuted. The standard deviation of wage differences in the subsample of stayers is 2.617 as opposed to its theoretical value of 0 . Nonetheless, the variance of wage differences among movers is far less than it is among stayers [where it is 5.011], which is consistent with my theoretical analysis. The main reason for the large difference is the correlation between 1997 and 1998 wage rates. In the sample of movers this correlation is only .279 whereas in the sample of

\footnotetext{
${ }^{17}$ To generalize, researchers using U.S. data often find that wage growth is greatest for "voluntary" movers and smallest for "involuntary" movers, with stayers having intermediate levels of wage growth. Since we would suspect that the subsample of movers contains a large proportion who move "voluntarily," there is no reason to expect this empirical result on the basis of a model of efficient separations. See Flinn $(1986,1997)$ for example, for further discussion of these issues.
} 
stayers it is .752 .

Though the stationarity assumptions underlying this analysis are surely suspect, a cautious conclusion is that the results are not inconsistent with the minimum wage change of September 1997 having had a beneficial effect on all labor market participants in this age range. It is the case, however, that the distribution of wage changes fails to satisfy two of the strong predictions of the model.

6. Conclusion

While it is tempting to infer the welfare effects of minimum wage changes from empirical observations on pre- and post-change wage distributions, in this exercise I have attempted to point out the hazards of doing so. I have focused on wage distributions in this paper, but this statement applies with equal force to the case in which the lack of change in employment levels following a minimum wage increase is taken to imply welfare increases. The welfare criterion employed in this paper, which is motivated by a simple equilibrium matching and bargaining model, reflects both employment probability and wage distribution effects of minimum wage changes and hence is preferable to any measure which takes into account only employment or wage information. Although the value of the welfare measure we have chosen is open to question, we would argue that whatever measure is finally chosen, a formal model of the labor market is required to meaningfully interpret minimum wage impacts on labor market outcomes.

The small empirical application I have presented usefully summarizes the general points I wish to make. First, the fact that the wage offer distribution in 1998 first order stochastically dominates the 1997 wage offer distribution does not necessarily imply an increase in welfare. Second, while I found no evidence of spillover resulting from the minimum wage increase of September 1997, within the context of my model this could only be taken to imply that there 
were no welfare effects of the minimum wage increase if the matching distribution satisfied condition 2 of Proposition 6. To determine if this is the case requires that specific tests be conducted using information from the wage distribution above the minimum or that the equilibrium model be directly estimated and tested. Third, I showed that the direction of wage changes for individuals who worked at the same job both before and after the minimum wage change and who were paid more than the relevant minimum wage in each period was consistent with welfare gains under the assumptions of my model. Using such data is perhaps the most straightforward way to assess the direction of welfare effects, but ideally one would like to adapt such a procedure to allow for limited forms of nonstationarity and population heterogeneity. Fourth, I have demonstrated that employment rate declines are perfectly consistent with increases in welfare. Finally, I have shown that the existence of spillover effects does not imply that a given minimum wage change was beneficial. Spillover can be good or bad, and can only be judged as beneficial within a particular model of the labor market. 
Table 1

Selected Sample Moments

Matched CPS Samples, March 1997-March 1998

\begin{tabular}{c|c|c|}
\multicolumn{1}{c}{} & \multicolumn{1}{c}{ Same Occ-Ind } & Diff. Occ-Ind \\
\cline { 2 - 3 } $\bar{w}_{1}$ & 7.678 & 7.747 \\
\cline { 2 - 3 } $\bar{w}_{2}$ & 8.692 & 8.353 \\
\cline { 2 - 3 } $\bar{w}_{2}-\bar{w}_{1}$ & 1.015 & .606 \\
\cline { 2 - 3 }$\hat{\sigma}_{1}$ & 3.298 & 4.743 \\
\cline { 2 - 3 }$\hat{\sigma}_{2}$ & 3.941 & 3.411 \\
\cline { 2 - 3 }$\hat{\sigma}_{1,2}$ & 9.774 & 4.514 \\
\cline { 2 - 3 }$\hat{\rho}_{1}$ & .752 & .279 \\
\cline { 2 - 3 }$\hat{\sigma}_{w_{2}-w_{1}}$ & 2.617 & 5.011 \\
\cline { 2 - 3 }$N$ & 92 & 153 \\
\cline { 2 - 3 }$N$
\end{tabular}




\section{References}

Bontemps, C., J.M. Robin, and G. van den Berg. 1999. "An Empirical Equilibrium Job Search Model with Search on the Job and Heterogeneous Workers and Firms." Intermational Economic Review. Forthcoming.

Bontemps, C., J.M. Robin, and G. van den Berg, G. 2000. "Equilibrium Search with Continuous Productivity Dispersion: Theory and Nonparametric Estimation." International Economic Review. Forthcoming.

Burdett, K., and D. Mortensen. 1998. "Wage Differentials, Employer Size, and Unemployment." International Economic Review 39: 257-273.

Card, D., and A. Krueger. 1995. Myth and Measurement: The New Economics of the Minimum Wage. Princeton: Princeton University Press.

Currie, J., and B. Fallick. 1996. "The Minimum Wage and the Employment of Youth: Evidence from the NLSY." Journal of Human Resources 31: 404-428.

Dickens, R., S. Machin, and A. Manning. 1997. "Estimating the Effect of Minimum Wages on Employment from the Distribution of Wages: A Critical View." Mimeo. Centre for Economic Performance, London School of Economics.

Dinardo, J., N. Fortin, and T. Lemieux. 1996. "Labor Market Institutions and the Distribution of Wages, 1973-1992: A Semiparametric Approach." Econometrica 64: 1001-1044.

Eckstein, Z. and K. Wolpin. 1990. "Estimating a Market Equilibrium Search Model from Panel Data on Individuals." Econometrica 58: 783-808.

Egge, K., A. Kohen, J. Shea, and F. Zeller. 1970. "Changes in the Federal Minimum Wage and the Employment of Young Men, 1966-67." In Youth Unemployment and Minimum Wages, Bulletin 1657, U.S. Department of Labor, Bureau of Labor Statistics: Government Printing Office.

Flinn, C. 1986. "Wages and Job Mobility of Young Workers." Journal of Political Economy 94: S88-S110.

Flinn, C. 1997. "Equilibrium Wage and Dismissal Processes." Journal of Business and Economic Statistics 15: 221-236.

Flinn, C. 1999. "Minimum Wage Effects on Labor Market Outcomes under Search with Bargaining." Mimeo. New York University.

Flinn, C., and J. Heckman. 1982. "New Methods for Analyzing Structural Models of Labor Force Dynamics." Journal of Econometrics 18: 115-68.

Heckman, J., and G. Sedlacek. 1981. "The Impact of the Minimum Wage on the Employment and Earnings of Workers in South Carolina." In Report of the Minimum Wage Study Commission, vol. 5. Washington, DC: Government Printing Office.

Linneman, P. 1982. "The Economic Impacts of Minimum Wage Laws: A New Look at an Old Question." Journal of Political Economy 90: 443-469.

Meyer, R., and D. Wise. 1983a. "Discontinuous Distributions and Missing Persons: The Minimum Wage and Unemployed Youth." Econometrica 51: 1677-1698. 
Meyer, R., and D. Wise. 1983b. "The Effects of the Minimum Wage on Employment and Earnings of Youth." Journal of Labor Economics 11: 66-100.

Mortensen, D. 1990. "Equilibrium Wage Distributions: A Synthesis," in Panel Data and Labour Market Studies, J. Hartog et al., eds. Amsterdam: North-Holland.

Neumark, D., and W. Wascher. 1995. "Minimum Wage Effects on School and Work Transitions of Teenagers." American Economic Review 85: 244-249.

Rao, C.R. 1973. Linear Statistical Inference and Its Applications, Second Edition. New York: John Wiley and Sons.

Smith, R., and B. Vavrichek. 1992. "The Wage Mobility of Minimum Wage Workers." Industrial and Labor Relations Review 46: 82-88.

van den Berg, G., and G. Ridder. 1998. "An Empirical Equilibrium Search Model of the Labor Market." Econometrica 66: 1183-1221. 
Figure 1.a

Match Value Density

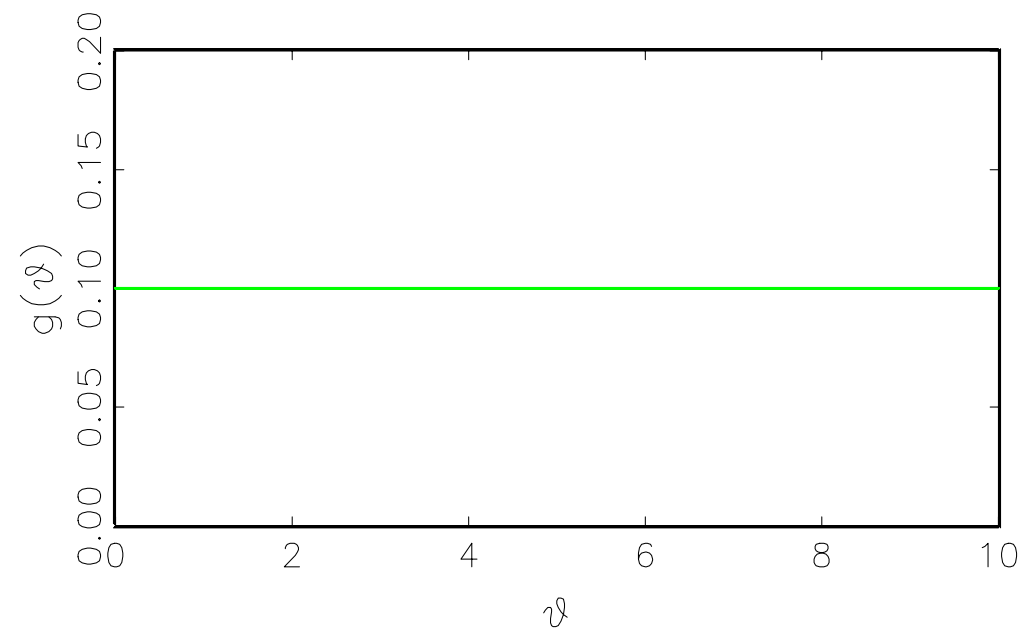

Figure 1.b

Equilibrium Wage Function

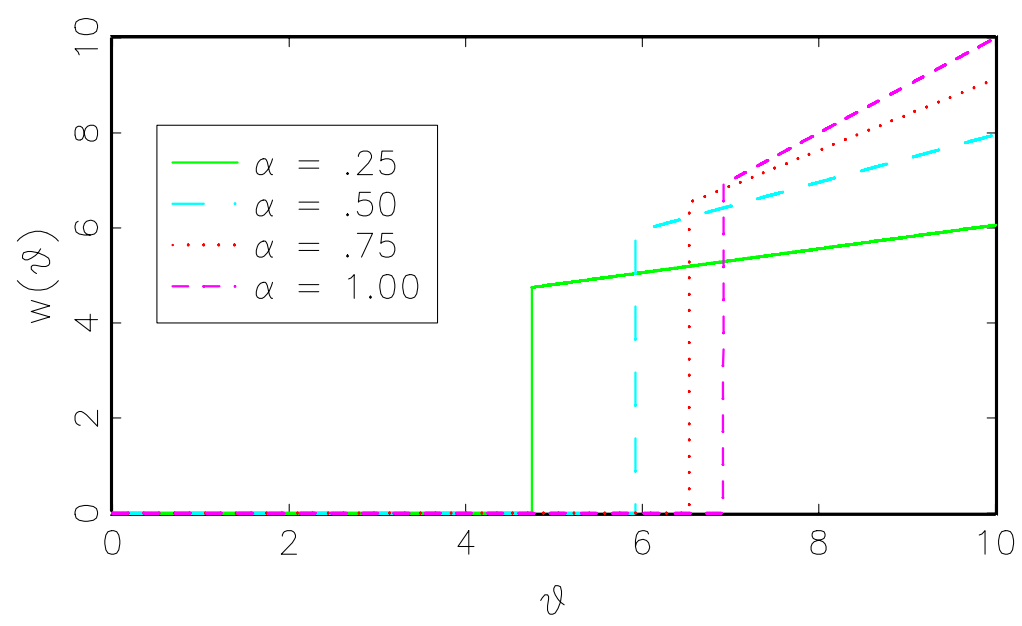


Figure 1.c

Wage Density

$\alpha=.25$

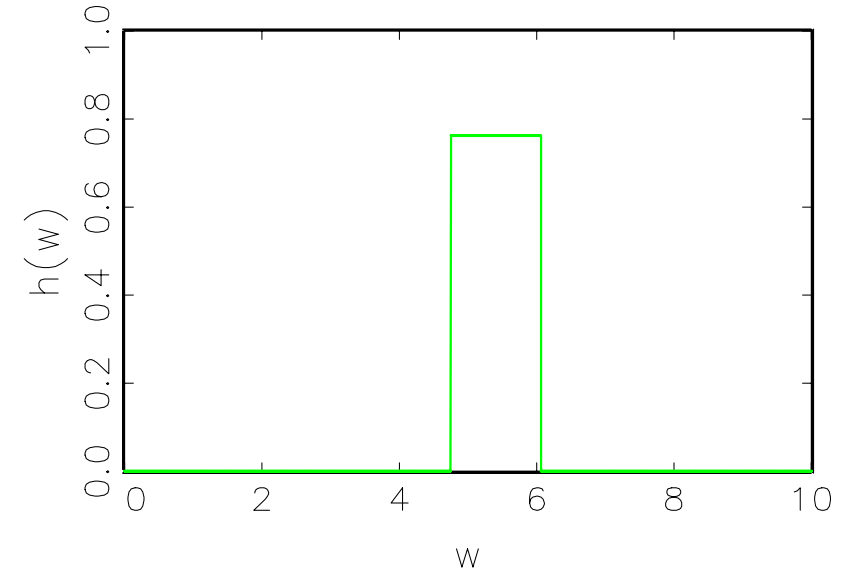

Figure 1.e

Wage Density

$\alpha=.75$

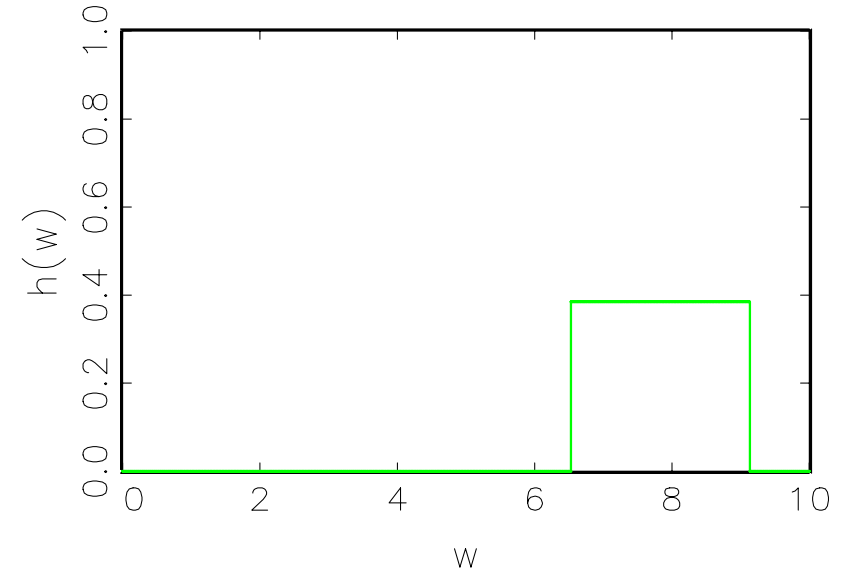

Figure 1.d

Wage Density

$\alpha=.5$

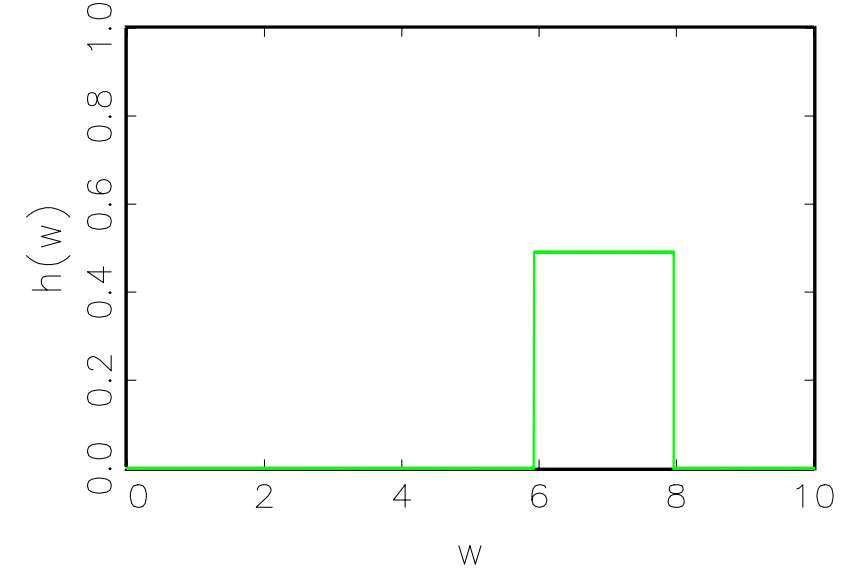

Figure 1.f

Wage Density

$\alpha=1$

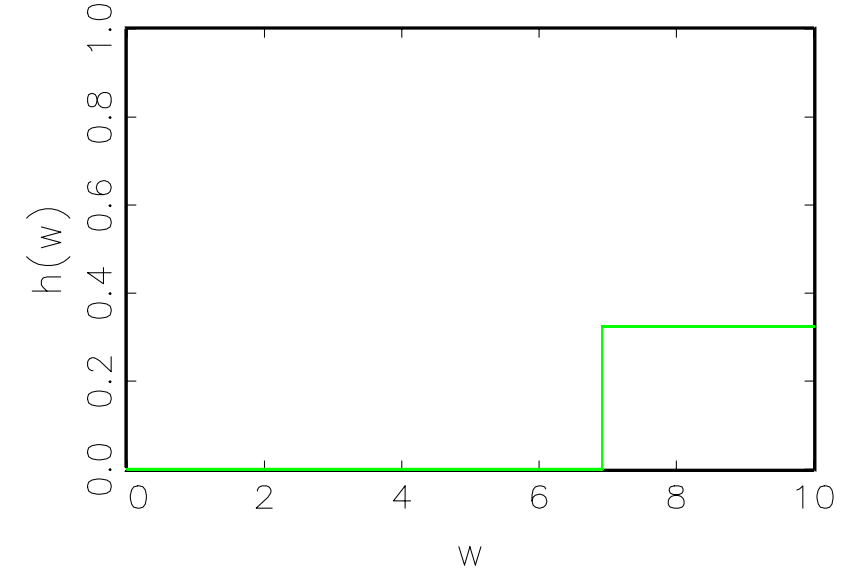


Figure 2.a

Match Value C.D.F.

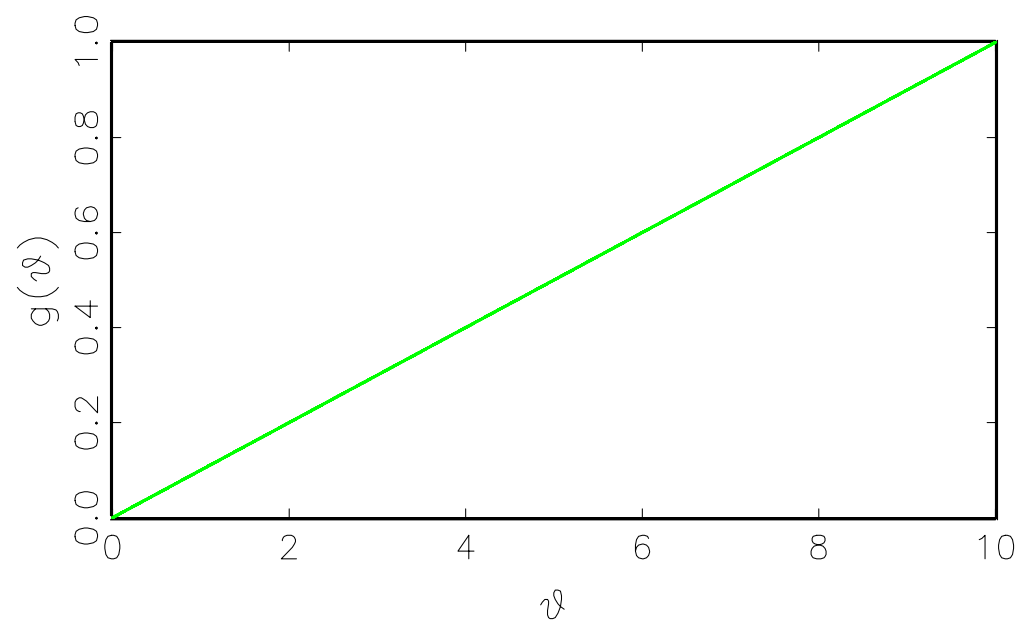

Figure 2.b

Equilibrium Wage Functions

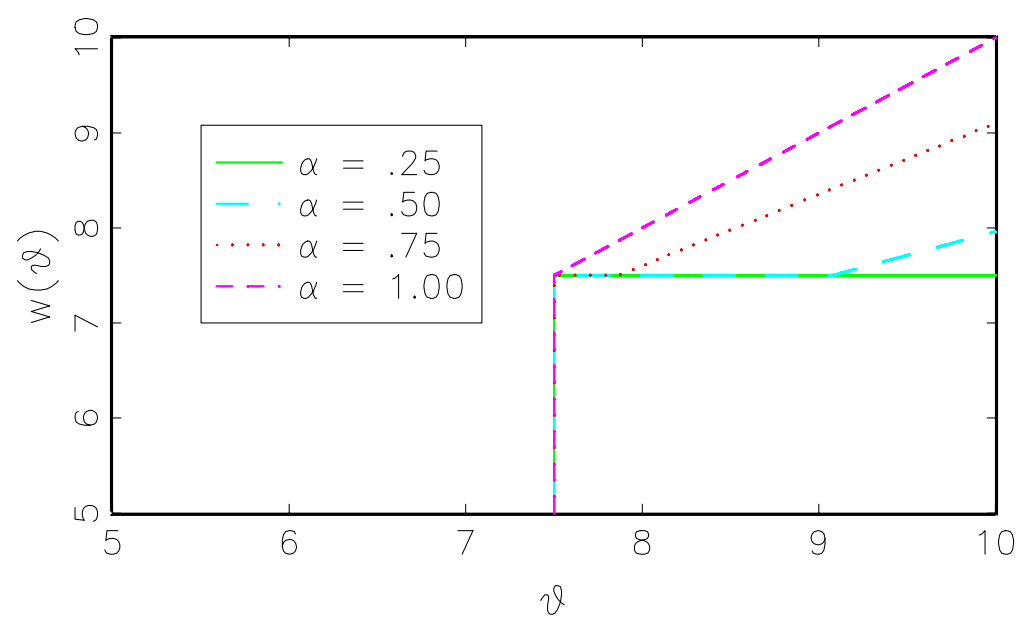


Figure 2.c

Wage C.D.F.

$\alpha=.25$

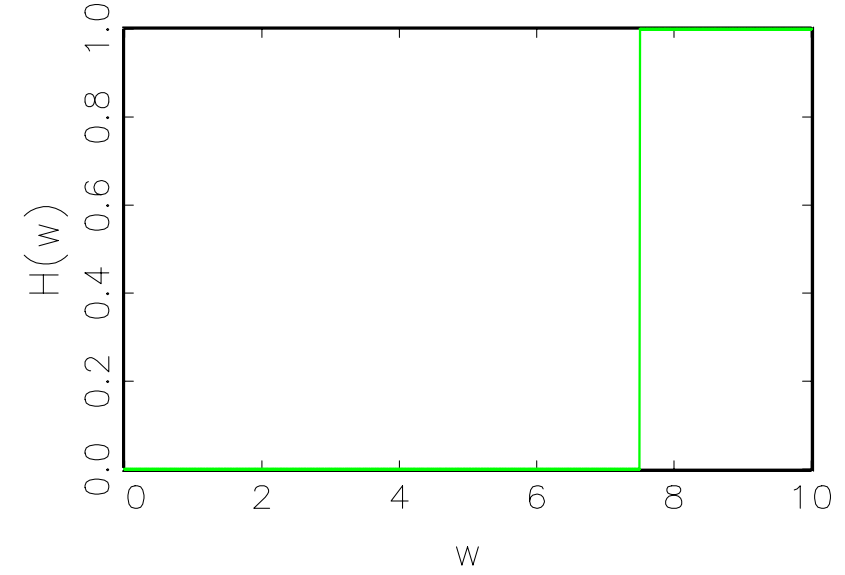

Figure 2.e

Wage C.D.F.

$\alpha=.75$

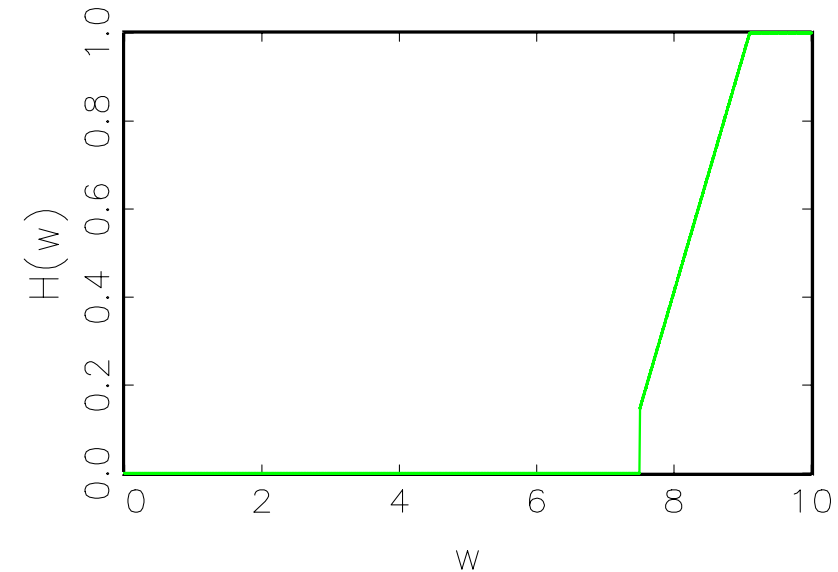

Figure 2.d

Wage C.D.F.

$\alpha=.5$

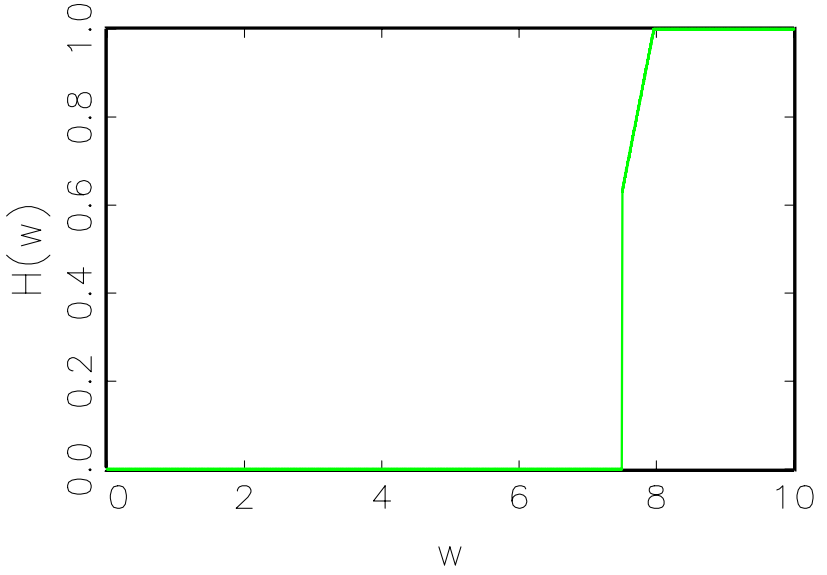

Figure 2.f

Wage C.D.F.

$\alpha=1$

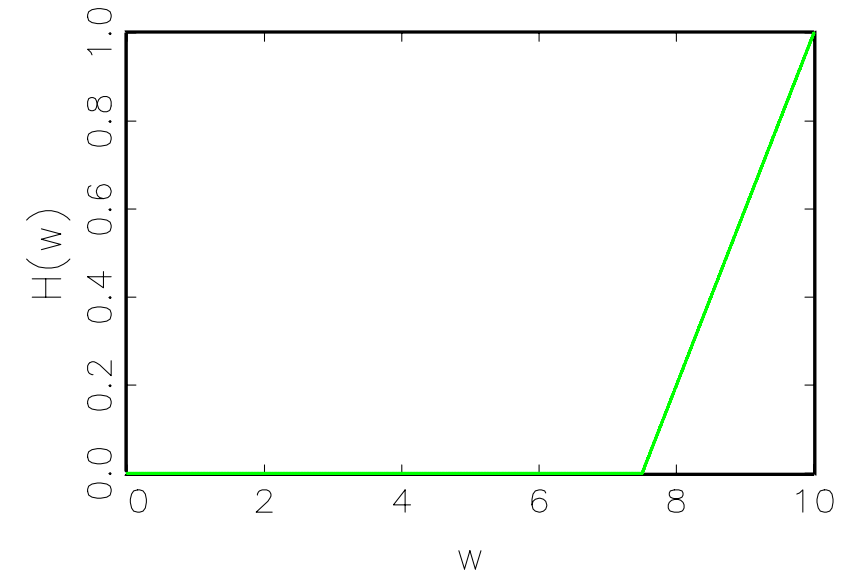


Figure 3.a

Wage C.D.F

$\alpha=.5$

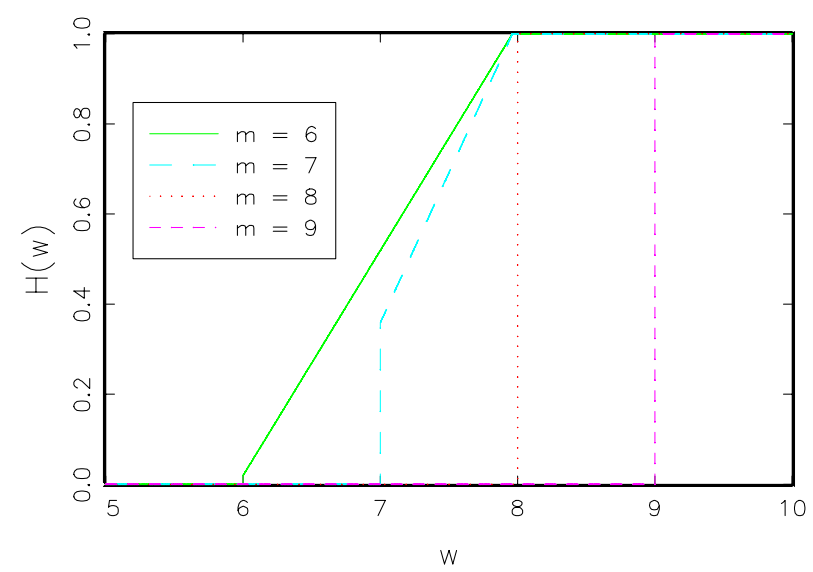

Figure 3.C Wage C.D.F $\alpha=.8$

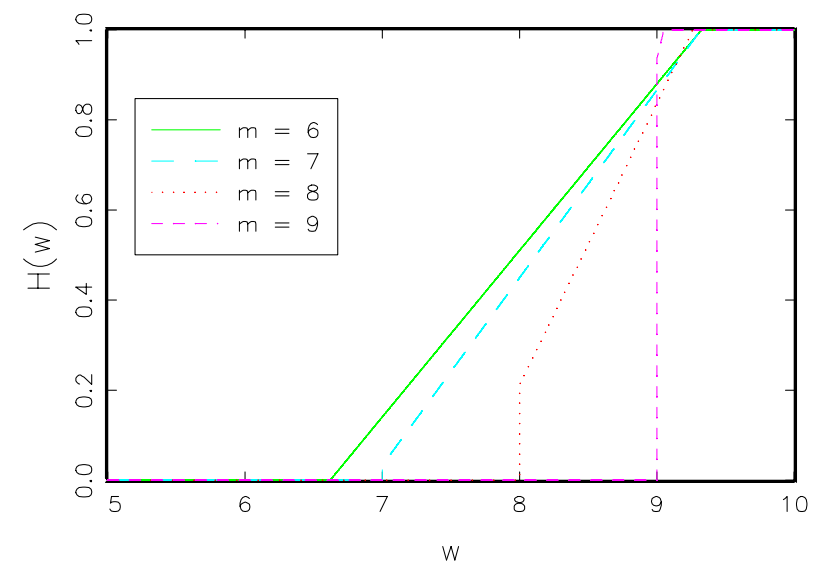

Figure 3.b

Wage C.D.F

$\alpha=.7$

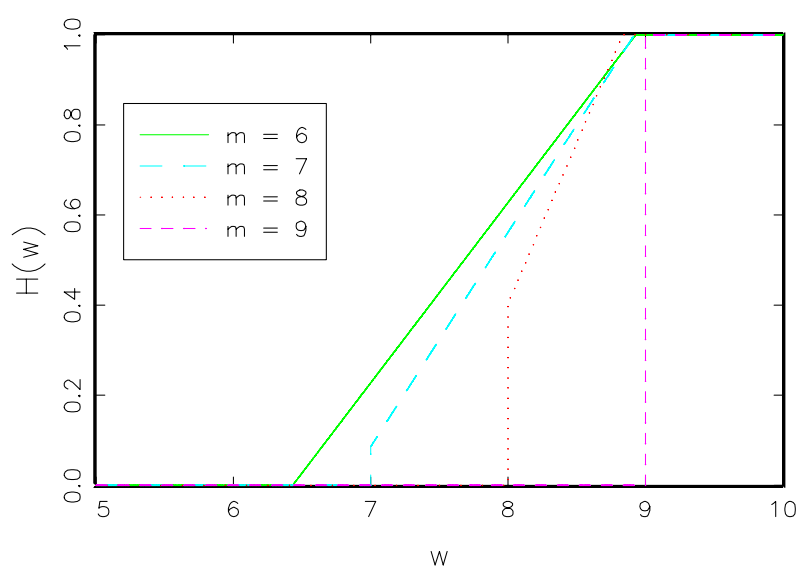

Figure 3.d Wage C.D.F $\alpha=.9$

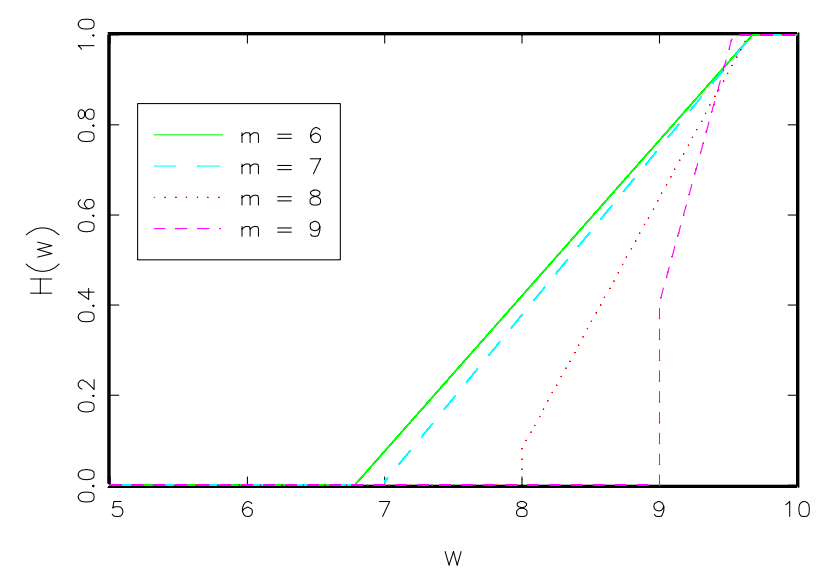


Figure 4.a

Hourly Wage C.D.F.

Log Normal Distribution, $m=5$

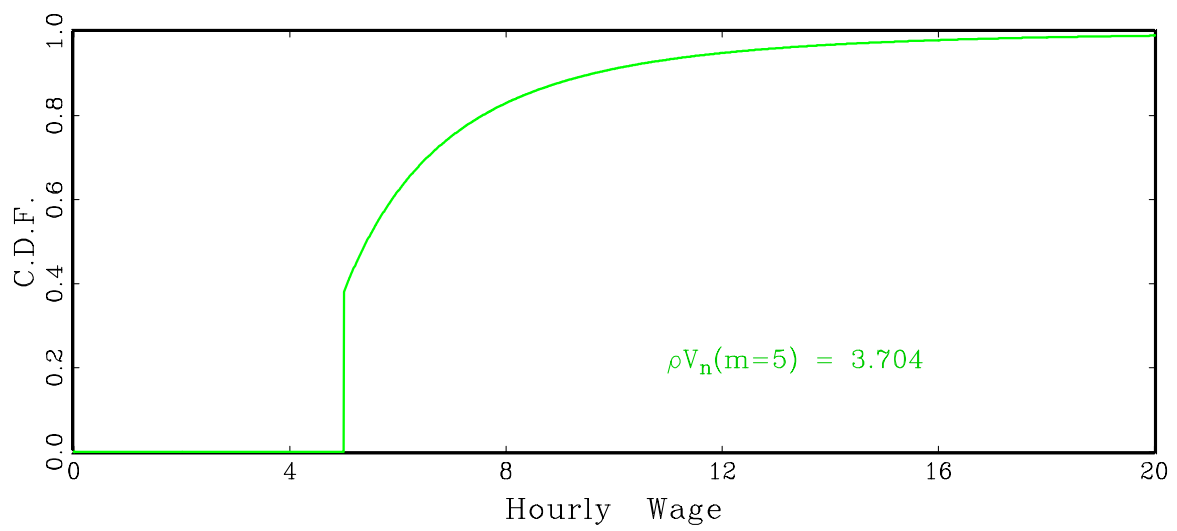

Figure 4.c

Hourly Wage C.D.F.

Log Normal Distribution, $m=7.50$

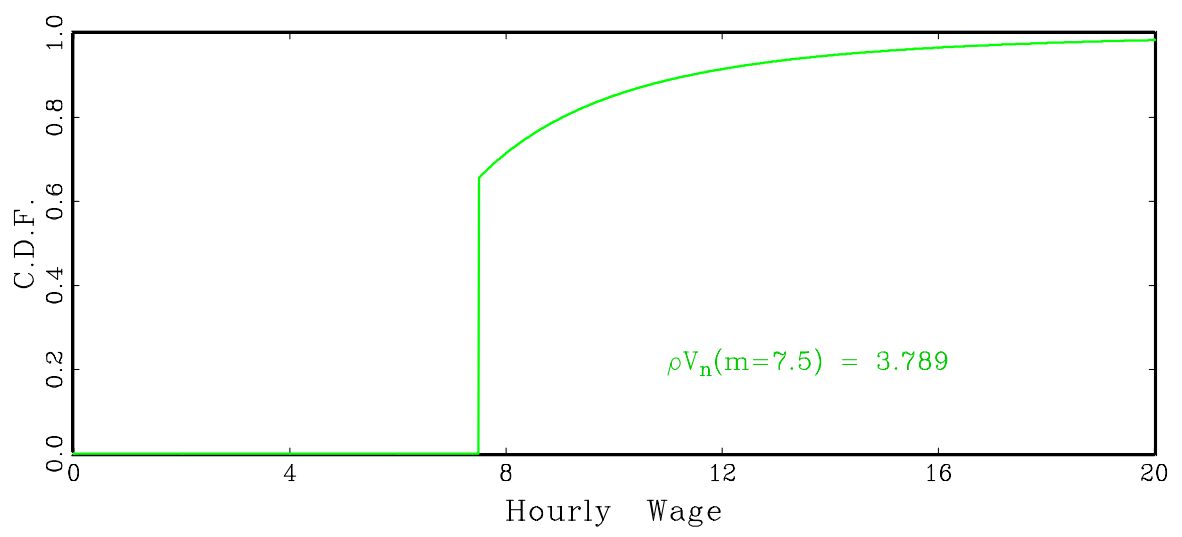

Figure 4.e

Hourly Wage C.D.F.

Log Normal Distribution, $m=10$

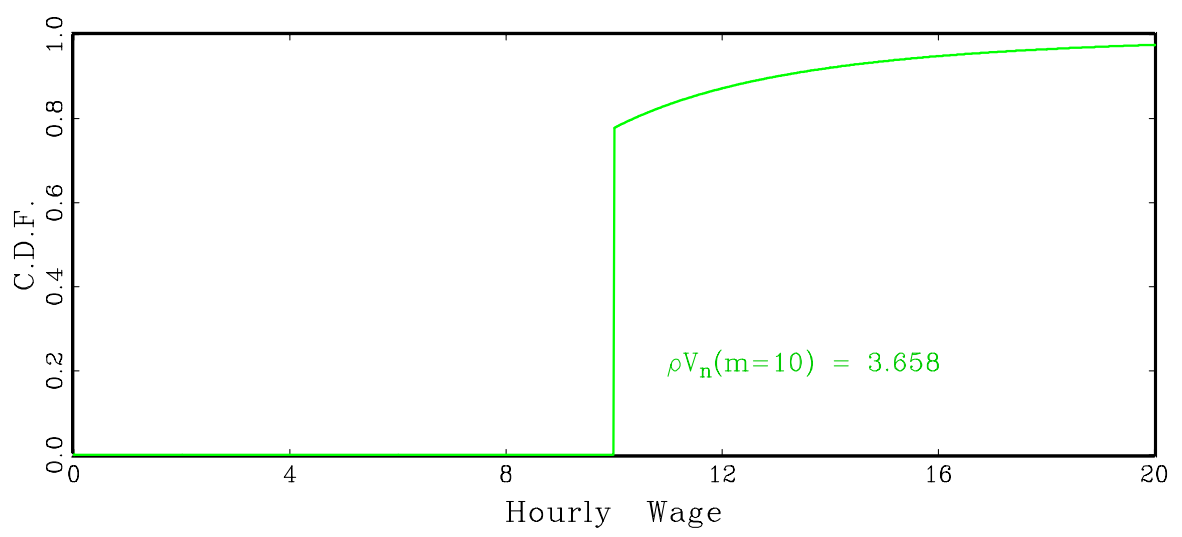


Figure 4.b

Hourly Wage C.D.F.

Exponential Distribution, $\mathrm{m}=5$

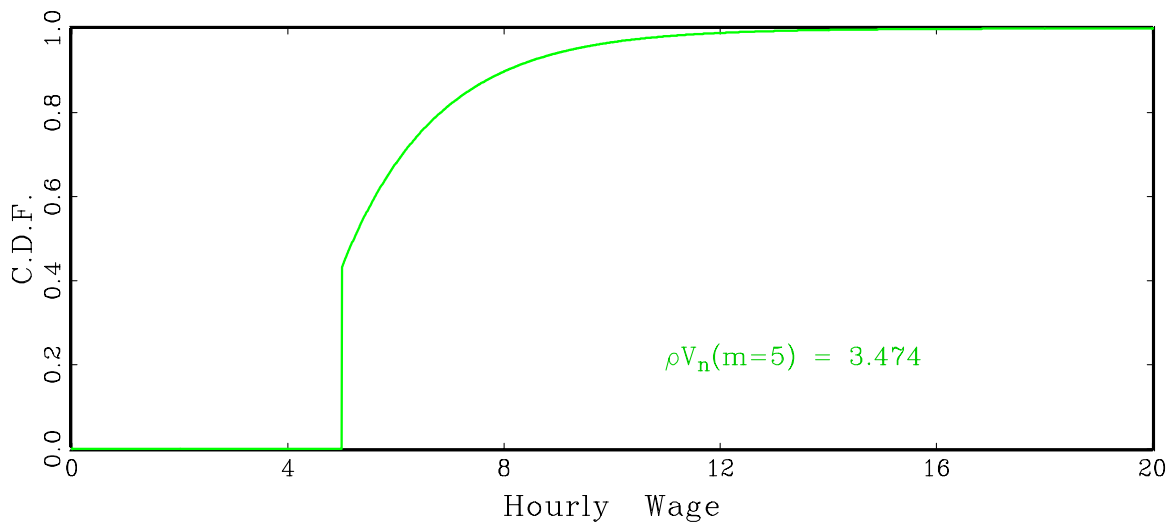

Figure 4.d

Hourly Wage C.D.F.

Exponential Distribution, $\mathrm{m}=7.50$

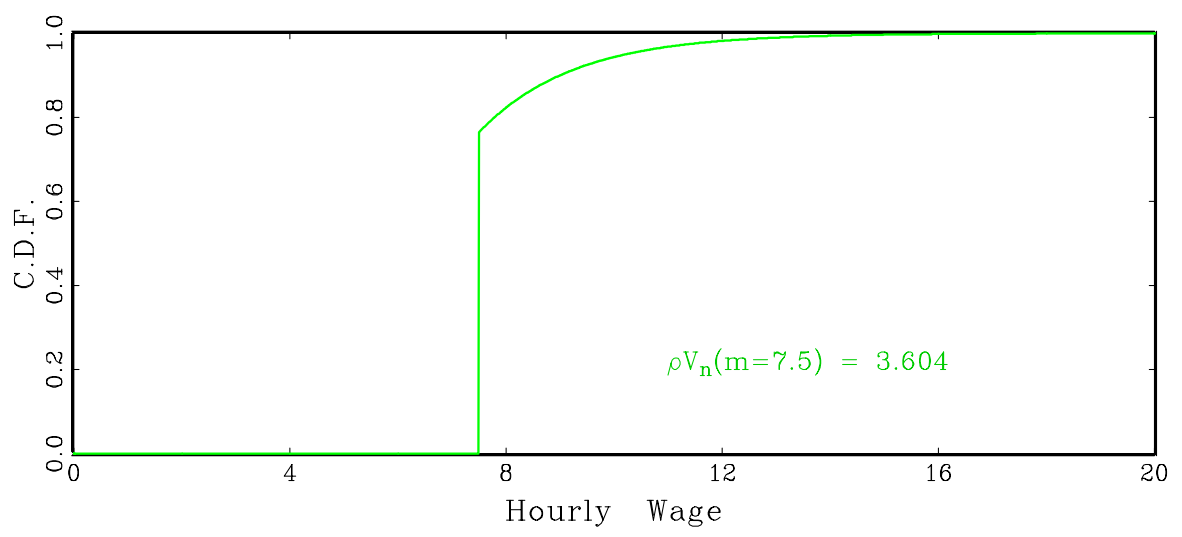

Figure 4.f

Hourly Wage C.D.F.

Exponential Distribution, $m=10$

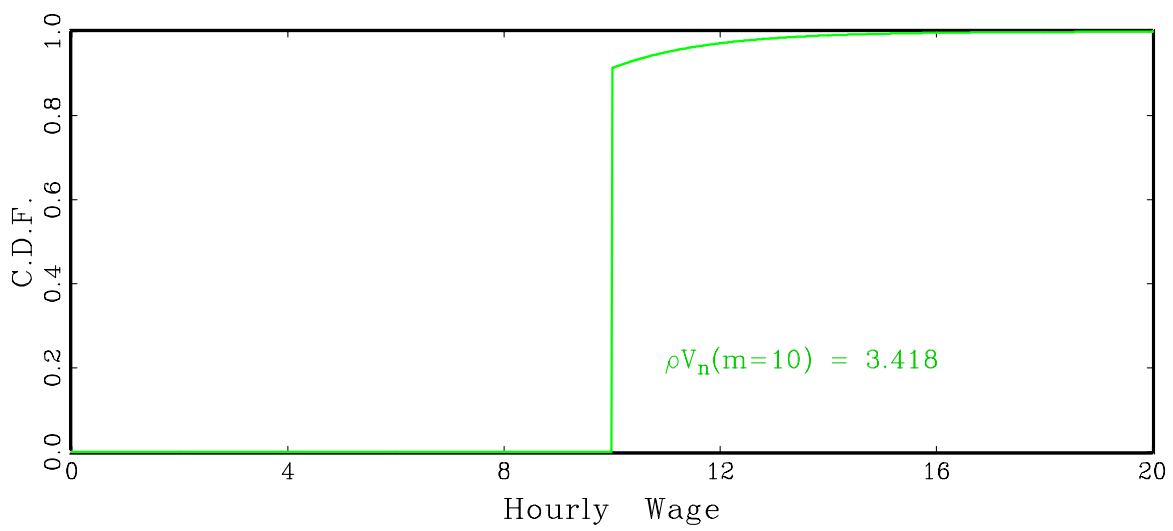


Figure 5.a

Log Normal Distribution

Minimum Wage 7.50 vs. 5.00

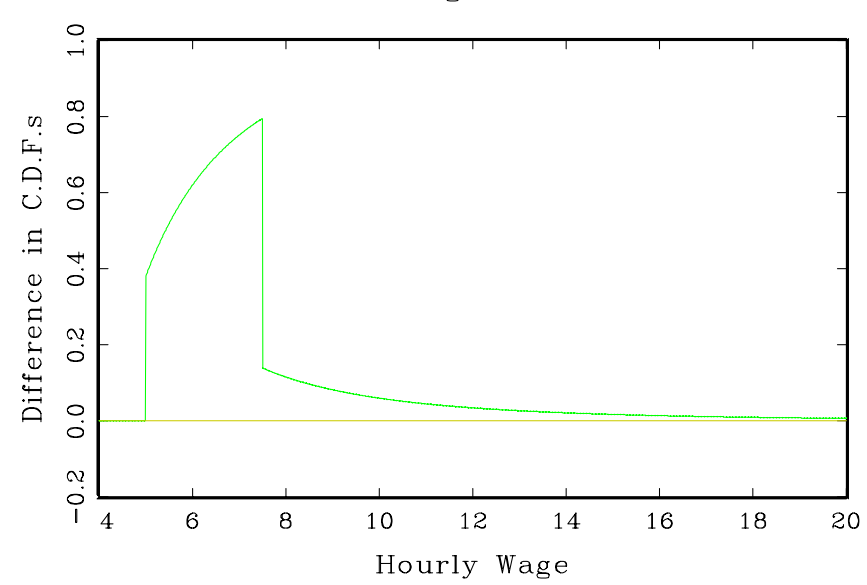

Figure 5.c

Log Normal Distribution

Minimum Wage 10.00 vs. 5.00

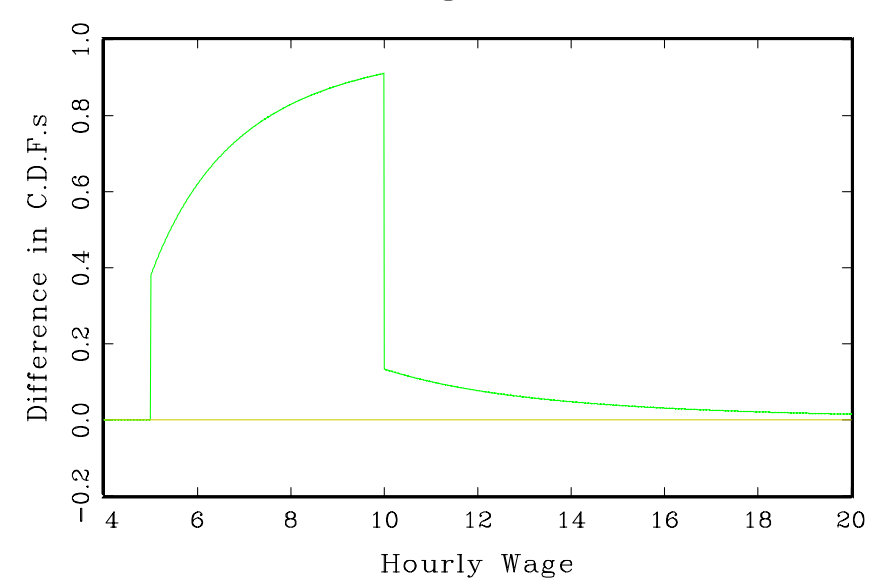

Figure 5.b

Exponential Distribution

Minimum Wage 7.50 vs, 5.00

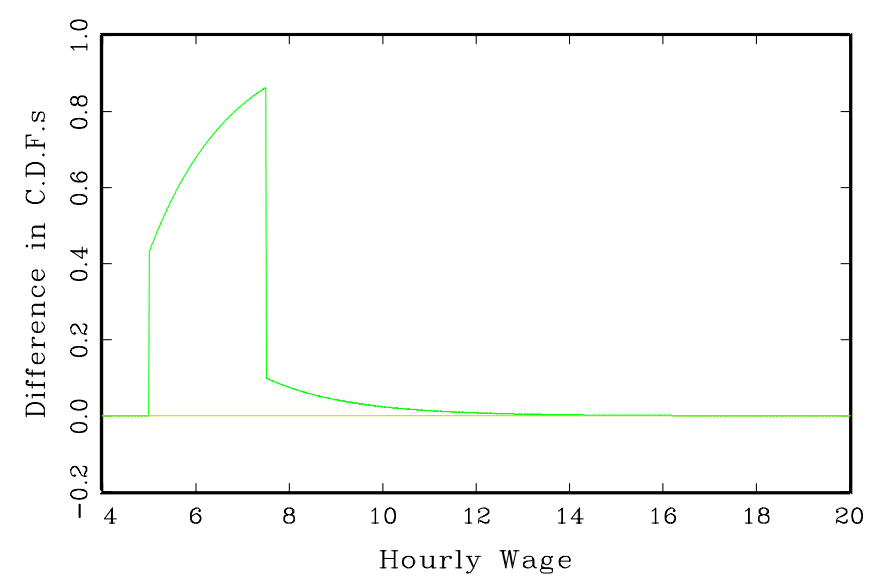

Figure 5.d

Exponential Distribution

Minimum Wage 10.00 vs. 5.00

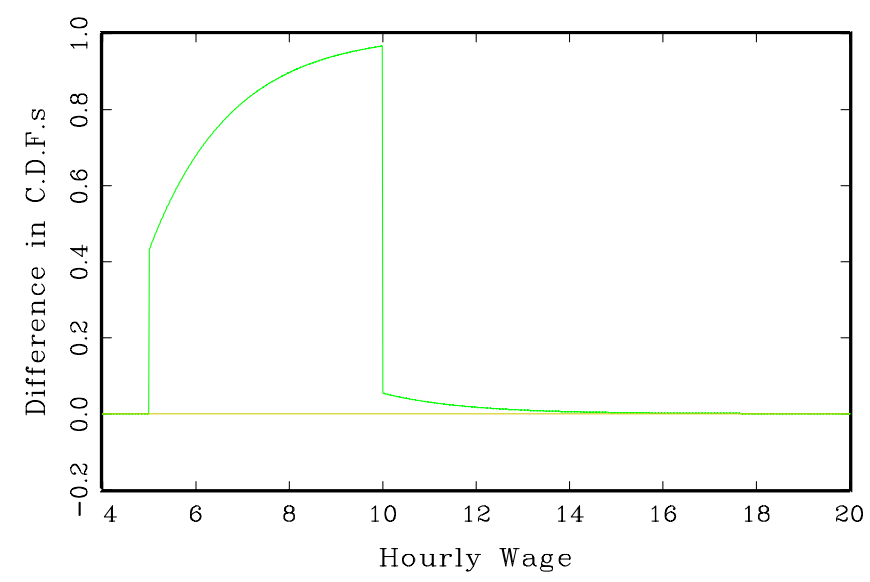


Figure 6.a

Log Normal Distribution

Minimum Wage 7.50 vs. 5.00

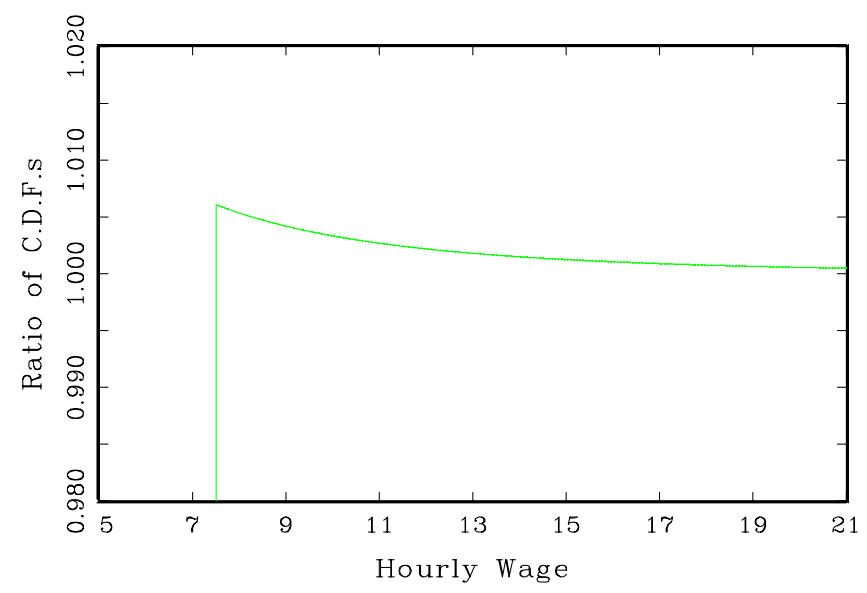

Figure 6.c

Log Normal Distribution

Minimum Wage 10.00 vs. 5.00

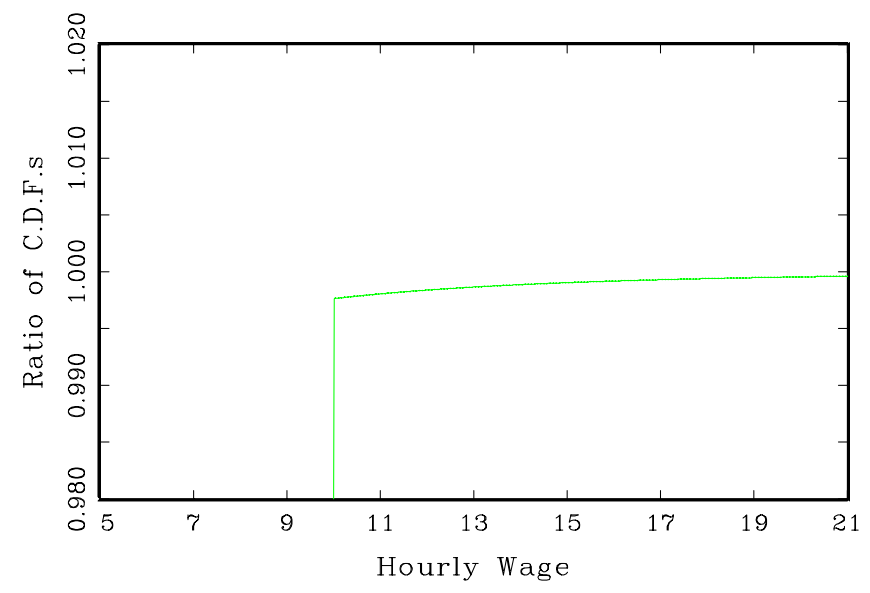

Figure 6.b

Exponential Distribution

Minimum Wage 7.50 vs. 5.00

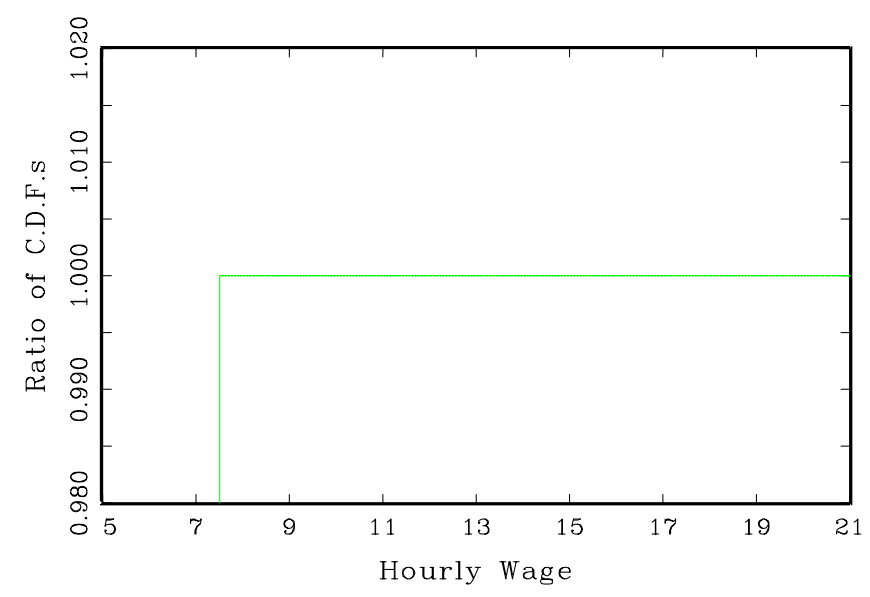

Figure 6.d

Exponential Distribution

Minimum Wage 10.00 vs. 5.00

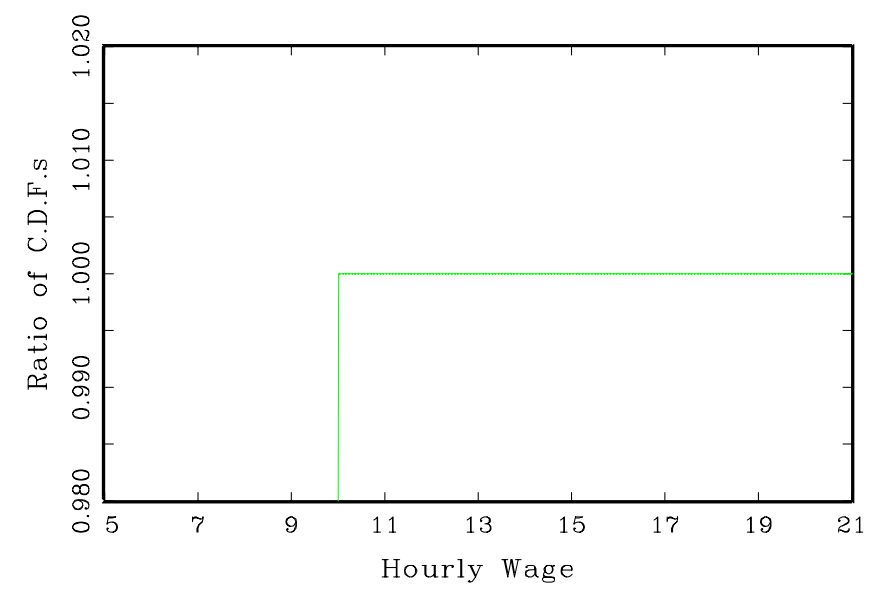


Figure 7.a

Histogram of Hourly Wage Rates

All Employees 16-24, March 1997

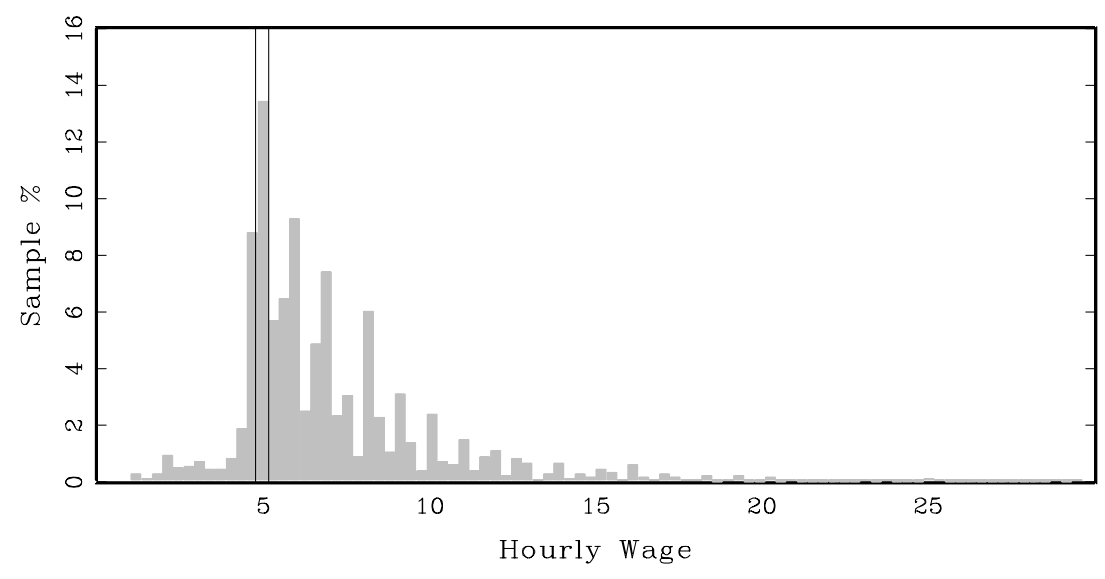

Figure 7.b

Histogram of Hourly Wage Rates

All Employees 16-24, March 1998

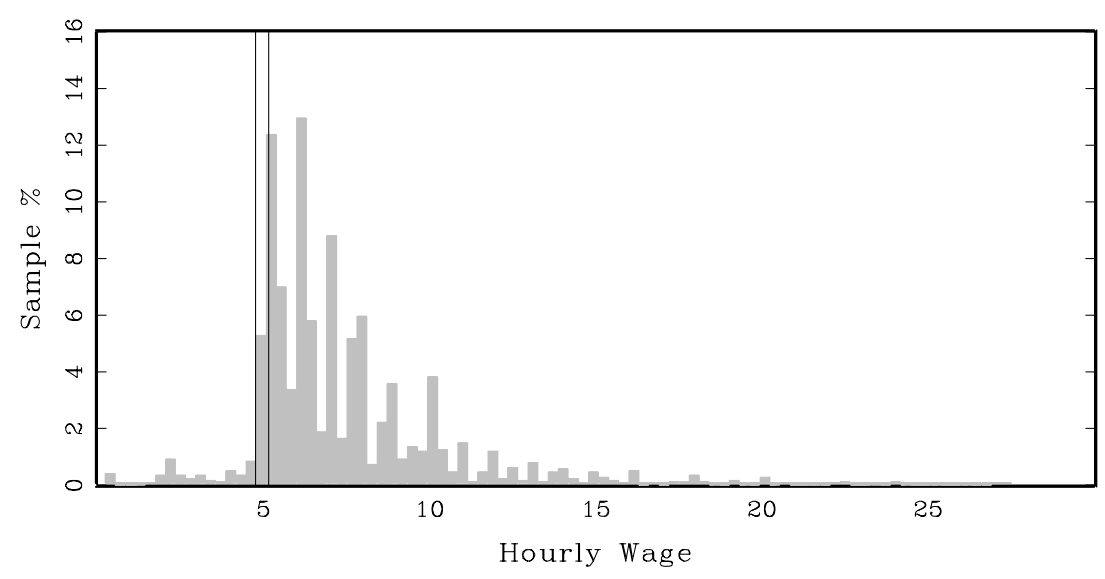


Figure 8.a

Empirical C.D.F.s

March 1997 and 1998 CPS

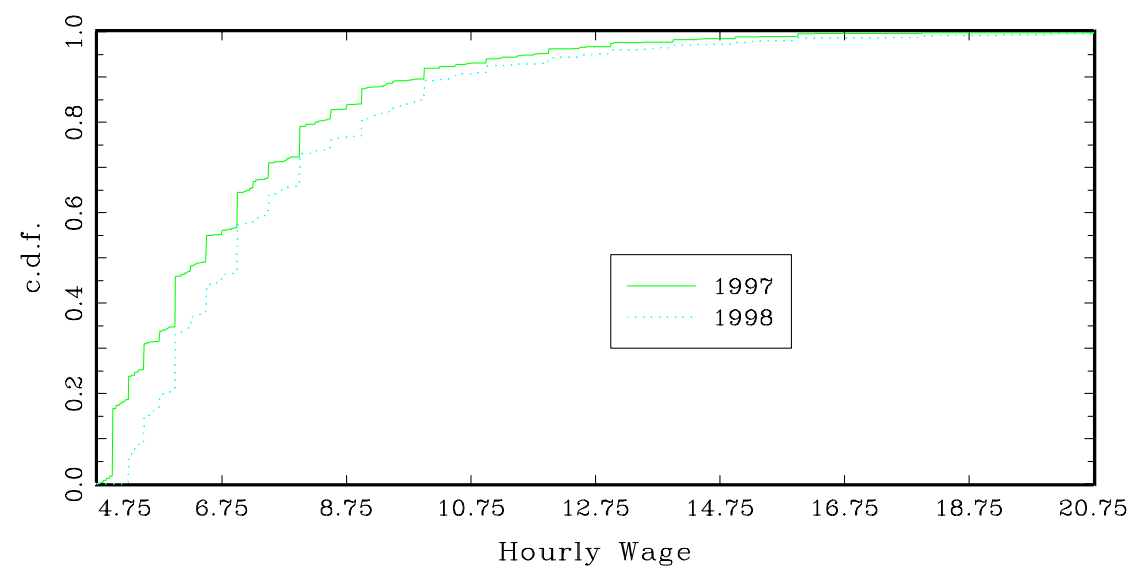

Figure 8.b

Difference in 1998 and 1997 Empirical C.D.F.s

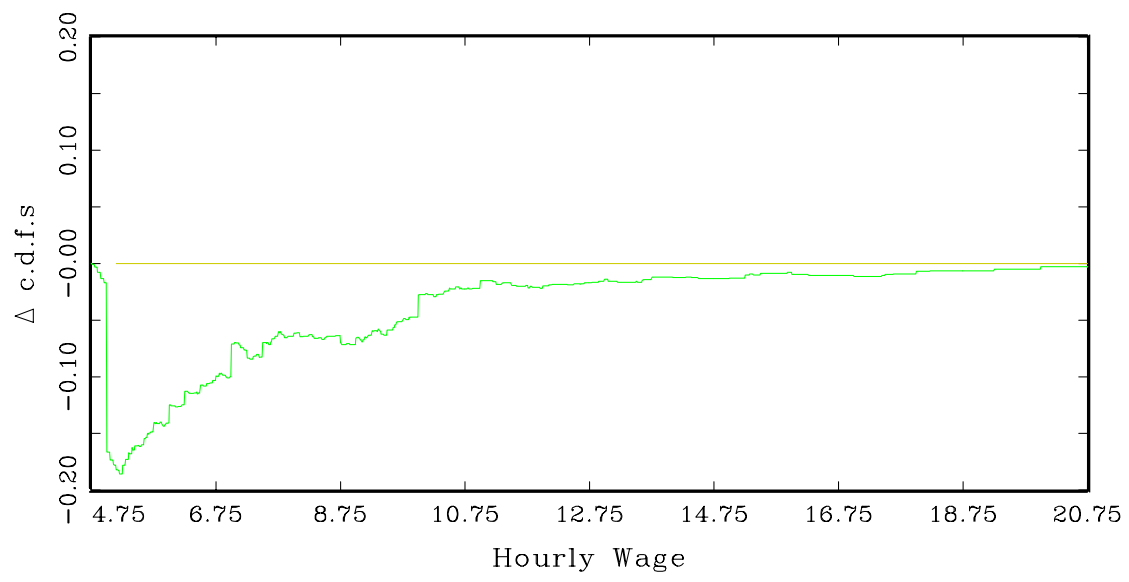


Figure 9.a

Empirical Conditional C.D.F.s

March 1997 and 1998 CPS

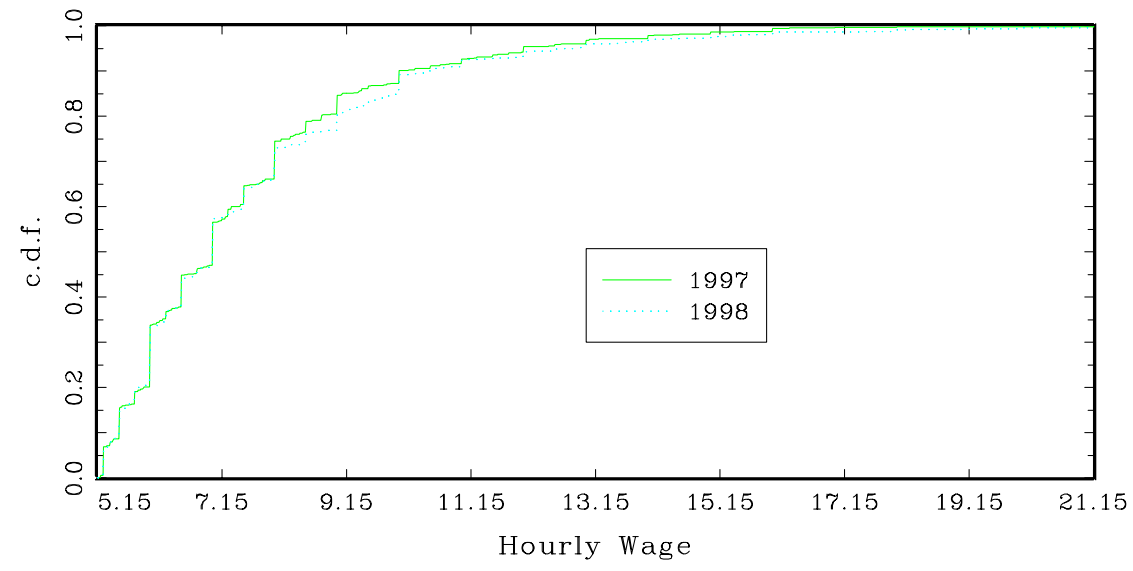

Figure 9.b

Difference in 1998 and 1997 Conditional C.D.F.s

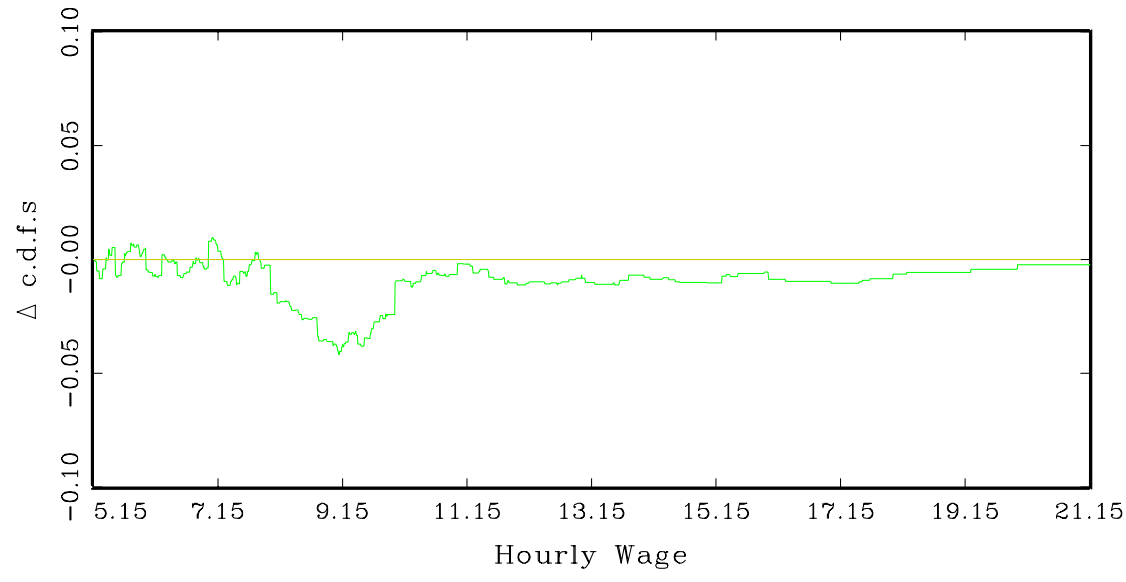

